\title{
RELATIONSHIP BETWEEN GREEN PUBLIC PROCUREMENT CRITERIA AND SUSTAINABILITY ASSESSMENT TOOLS APPLIED TO OFFICE BUILDINGS
}

\section{Abstract}

Green Public Procurement (GPP) plays an important role in facing the challenge of reducing the environmental impacts from construction sector-related products, services and works, and creating environmental and innovative value for society in favour of a greener and more sustainable economy. The European Commission recently developed GPP criteria for the "office buildings" category. In parallel, Building Sustainability Assessment (BSA) tools help estimate a building's impact on the environment based on a life cycle approach. Many of the aspects and measurable indicators included in BSA tools are clearly related to the criteria covered by GPP. However, other important ones are missing and should be integrated to ensure green procurement initiatives. This study critically reviews the GPP criteria proposed for office buildings and crosschecks them with the sustainability indicators included in three BSA tools to reinforce the GPP framework for the office buildings sector. It provides, on the one hand, an evaluation of the rate of improvement achieved in the tools when applying GPP criteria and, on the other, a proposal for a weighting system for awarding points to the offers in tenders. The results will help contracting authorities to introduce more objectivity into the tendering process and to make informed decisions while evaluating bidders' proposals.

Keywords: green public procurement; sustainable public procurement; construction sector; office buildings; sustainable buildings 


\section{Introduction}

The construction sector, which accounts for $10 \%$ of the GDP (Gross Domestic Product) and employs about $7 \%$ of the workforce in the European Union (EU), is one of the leading markets in which to boost competitiveness and promote sustainable solutions. Buildings not only account for the largest share of the EU's total final energy use (42\%), but also generate about $35 \%$ of all greenhouse emissions. Construction and demolition work accounts for about $33 \%$ of the waste generated annually, and more than $50 \%$ of all the natural resource materials are transformed into construction materials and products (European Communities 2007). Thus, the construction sector's potential to reduce environmental impacts is evident.

Green Public Procurement (GPP) and labelling/certification schemes are two of the main policy instruments used to meet the challenge of both reducing environmental impacts from construction sector-related products, services and works, and creating environmental and innovative value for society in favour of a greener and more sustainable economy. GPP is defined as "a process whereby public authorities seek to procure goods, services and works with a reduced environmental impact throughout their life-cycle when compared to goods, services and works with the same primary function that would otherwise be procured" (COM 400 2008). For public organisations, GPP can work as a market incentive to enhance green initiatives in the private sector, while it has been suggested that it can also result in reduced risk and cost for private organisations (Varnäs et al. 2009).

The European Commission (EC) developed specific environmental criteria for the category of office buildings, which in the EU GPP context are considered as "buildings whose primary function is to provide space for administrative, financial, professional or customer services" (European Commission 2016b). In relation to the construction sector, while GPP is a voluntary instrument, there is specific mandatory EU legislation that regulates the environmental performance of office buildings. For example, the EU Energy Efficiency Directive (European Commission 2012) urges governments to purchase only products, services and buildings with high energy-efficiency performance that are consistent with cost-effectiveness, economic feasibility, wider sustainability, technical suitability and sufficient competition. The recast of the Energy Performance of Buildings Directive (EPBD 2010) stated that all new public buildings had to become Near-Zero Energy Buildings (NZEB) by 2018, a challenge still to be met. These compulsory considerations must be, and in fact are, increasingly integrated as GPP criteria for office buildings.

In recent years, GPP has evolved towards Sustainable Public Procurement (SPP), which includes the integration of socio-economic considerations in the public procurement of assets, in addition to existing environmental ones. Many countries have set targets and have adopted national action plans for SPP (Uttam and Le Lann Roos 2015). The action plan of Nordic countries (Nordic Council of Ministers 2010), pioneers in public procurement, went a step further and introduced the term Innovative Green Public Procurement (IGPP), which they described as one of the key tools towards more sustainable production and for promoting ecoinnovation. Whatever terminology is used - GPP/SPP/IGPP - the procurement of office buildings becomes a particularly complex process that necessarily results in the fact that including environmental, social and innovative preferences requires increased expertise, greater verification efforts and higher upfront costs (Dodd et al. 2016), and this usually implies an increase in the cost of a product or service. This generally means that more sustainable goods and services are also more expensive and tend not be purchased. In fact, as highlighted by Testa et al. (2016), financial issues are one of the main barriers for GPP worldwide, and thus there is a tendency to select the cheapest alternatives. However, positive relationships have been identified between GPP and Life Cycle Costing (LCC), demonstrating that higher initial costs of goods may involve lower associated costs during lifetime, since the LCC approach quantifies a number of options with the objective of defining the optimum selection of goods 
taking into account all the significant costs involved in the service life of the goods (Giacomo et al. 2018).

During the bidding process, public tender documents usually include a mixture of technical, economic, work condition-related, social, ethical, environmental and innovation specifications, and allocate a weight percentage to each of them at their own discretion, since EU GPP proposes a set of criteria but not a weighting system for them. Although environmental considerations are increasingly taken into account during procurement in the European context, they only represent around $10 \%$ of the overall weight, and economic specifications are still the most relevant ones (Uttam and Le Lann Roos 2015). Hence, environmental issues seldom have an impact on the outcome of the procurement process (Varnäs et al. 2009). For instance, a content study examining public tenders for the construction sector in Italy (Testa et al. 2016) showed that only $35 \%$ of tenders could be classified as "green", and $32 \%$ of tenders did not include any form of environmental criteria. These findings mean that public authorities do play an important role. As pointed out in Directive 2014/24/EU on public procurement (European Commission 2014), they hold the key to improve the efficiency and quality of public services. At the same time they also help to achieve the best value for public money, as well as wider economic, environmental and societal benefits to generate new ideas by translating them into innovative assets and, thus, to promote sustainable economic growth. As a result, the level of ambition chosen for the tender procedure will necessarily depend on the contracting authority's knowledge and experience, the scale of the project, and a judgement of potential bidders' level of experience.

Conversely, and in line with the environmental assessment of buildings, Building Sustainability Assessment (BSA) tools were created after reckoning the impact of building sector activities on the environment and socio-economic contexts, with the aim of establishing comprehensive means of simultaneously assessing a broad range of environmental considerations in buildings (Haapio and Viitaniemi 2008). Now, these are also presented as a key instrument to add circular economy to the construction sector, and efforts are being made to unite tools and actors through the development of a common framework of sustainability indicators for residential and office buildings (Dodd et al. 2017). Consequently, the integration of BSA and GPP has a potential to be explored and, in fact, some of the indicators included in the BSA tools have been taken into account to formulate some environmental GPP criteria (Varnäs et al. 2009; Dodd et al. 2016). Yet despite the need to strengthen the relationship between GPP and BSA tools, this has not been consistently confirmed, and no work has been found in the literature that approaches this issue.

In this context, the purpose of the present study is to identify the gap between EU GPP and BSA criteria and to show how the two tools can be integrated to facilitate the implementation of EU GPP by public authorities during tender evaluation processes, thereby reinforcing the GPP framework for the office buildings sector. To this end, the work critically reviews the criteria proposed in EU GPP for office buildings and crosschecks it with the sustainability indicators included in a set of BSA tools specifically designed for tertiary buildings. The findings of the study provide two main results. One of them is an evaluation of the improvement in the rating achieved in the BSA tools when GPP criteria are applied. The other is a proposal to apply weighting criteria (based on the BSA weighting criteria) when awarding points to the offers of tenders in order to assist public authorities during the bidding evaluation process.

The findings will make it possible to identify how integrating not only environmental but also socio-economic sustainable criteria into the public procurement process of the construction sector can make GPP more effective, and how the completion of more cost-efficient innovative office buildings can be achieved. Integrating BSA considerations is likely to help public contracting authorities introduce more objectivity into the tendering process by preparing 
documents and establishing a system of points so that authorities can make informed decisions while evaluating bidders' proposals.

\section{Background}

\subsection{Green Public Procurement (GPP)}

The earliest efforts made in public procurement with specific environmental connotations can be found in Sweden, where Sterner (2002) examined the stipulated environmental aspects when procuring building projects, and identified the difficulties involved in evaluating them by making it quite clear that there is a need for methods that assist in the evaluations tenders make of the environmental criteria. Consistent with this idea, a number of authors such as Uttam and Balfors (2014), Fuentes-Bargues et al. (2017), D'Hollander and Marx (2014), Dodd et al. (2016) and Mahmoud et al. (2019) agree that the incorporation of methods such as the Life Cycle Assessment (LCA) subjected to ISO 14040 (2006) and to ISO 14044 (2006), Environmental Management Systems (EMS) (European Commission 2009a; ISO 14001 2015) or Eco-labelling (European Commission 2009b), among others, currently facilitates this task.

Table 1 presents the literature review in the field of GPP that deals specifically with the construction sector. Varnäs et al. (2009) found that environmental criteria are usually considered as requirements but rarely affect the award decisions set by the contracting authorities due to a fear of project delays, the desire to simplify the project and the risk of incurring in increased costs and limitations. Uttam and Balfors (2014) provided an overview of the growth of GPP among several European countries and beyond Europe, and highlighted the need for the bidder to demonstrate, before the contract is awarded, the ability to comply with the stipulated criteria. In another step, Uttam and Le Lann Roos (2015) analysed the consequences of changes in the weight of environmental requirements on contract award decision-making, and revealed that increasing this weight might not always ensure that GPP is implemented correctly. Also in relation to the weight of the criteria, Testa et al. (2016) determined that technical specifications and award criteria are the ones that include the most environmental requirements. Some other research has been carried out on specific case studies related to the construction sector: wooden windows (Tarantini et al. 2011), lighting systems (Deambrogio et al. 2017), educational buildings (Fuentes-Bargues et al. 2018) or netzero energy buildings (Sparrevik et al. 2018). Finally, with a more general approach regarding geographical and application scope, Montalbán-Domingo et al. (2018) identified the need to develop policies to promote the use of social and environmental criteria, together with metrics, in the awarding of the evaluation of projects in the construction industry. 
Table 1. GPP Literature review within the construction sector

\begin{tabular}{|c|c|c|c|c|c|c|c|c|c|c|c|c|c|c|c|}
\hline \multirow[b]{2}{*}{ Author/s } & \multirow[b]{2}{*}{ Country } & \multirow[b]{2}{*}{ Research method } & \multirow[b]{2}{*}{ 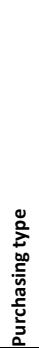 } & \multirow[b]{2}{*}{ 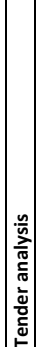 } & \multirow[b]{2}{*}{ 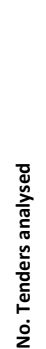 } & \multicolumn{7}{|c|}{ Scope } & \multicolumn{3}{|c|}{ Purpose } \\
\hline & & & & & & 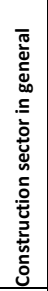 & 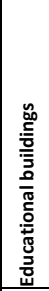 & 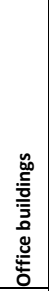 & $\begin{array}{l}\frac{n}{2} \\
\frac{3}{3} \\
\frac{3}{3}\end{array}$ & 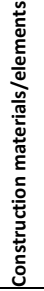 & 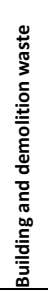 & 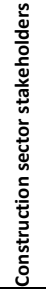 & 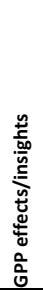 & $\begin{array}{l}\frac{\grave{0}}{\overline{0}} \\
\frac{0}{0} \\
0\end{array}$ & 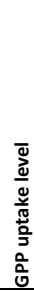 \\
\hline Sterner (2002) & SE & Interviews, survey & w & & & & & & & - & - & - & - & - & \\
\hline Varnäs et al. (2009) & SE & Interviews, survey & $\mathrm{w}$ & & & • & & & & & & $\bullet$ & & - & $\bullet$ \\
\hline Tarantini et al. (2011) & IT & LCA & $\mathrm{P}$ & & & & & & & $\bullet$ & & & $\bullet$ & $\bullet$ & \\
\hline Uttam and Balfors (2014) & SE,PL,NL,NZ,KR & Qualitative analysis & w & & & & & & & $\bullet$ & & & $\bullet$ & $\bullet$ & $\bullet$ \\
\hline Uttam and Le Lann Roos (2015) & SE & $\begin{array}{l}\text { Interviews, multicriteria } \\
\text { analysis, case study }\end{array}$ & w & $\bullet$ & 3 & & & & - & & & & & $\bullet$ & \\
\hline Testa et al. (2016) & IT & $\begin{array}{l}\text { Interviews, qualitative and } \\
\text { statistical analysis }\end{array}$ & w & $\bullet$ & 164 & $\bullet$ & & & & & & & & $\bullet$ & $\bullet$ \\
\hline Deambrogio et al. (2017) & IT & Case study & $P, S$ & & & & & & & - & & & • & - & \\
\hline Fuentes-Bargues et al. (2017) & EU, ES & $\begin{array}{l}\text { Qualitative and quantitative } \\
\text { analysis }\end{array}$ & w & $\bullet$ & 100 & $\bullet$ & & & $\bullet$ & & & & $\bullet$ & & $\bullet$ \\
\hline Fuentes-Bargues et al. (2018) & ES & $\begin{array}{l}\text { Qualitative and quantitative } \\
\text { analysis }\end{array}$ & w & $\bullet$ & 316 & & $\bullet$ & & & & & & $\bullet$ & $\bullet$ & \\
\hline Sparrevik et al. (2018) & NO & Case study & $w$ & & & $\bullet$ & & & & & & & $\bullet$ & $\bullet$ & \\
\hline $\begin{array}{l}\text { Montalbán-Domingo et al. } \\
(2018)\end{array}$ & $\mathrm{AR}, \mathrm{AU}, \mathrm{CA}, \mathrm{CL}, \mathrm{CO}, \mathrm{PA}, \mathrm{PE}, \mathrm{ES}, \mathrm{UK}, \mathrm{US}$ & $\begin{array}{l}\text { Quantitative and statistical } \\
\text { analysis }\end{array}$ & & $\bullet$ & 461 & $\bullet$ & & & $\bullet$ & & & & & $\bullet$ & $\bullet$ \\
\hline
\end{tabular}

\subsection{Building Sustainability Assessment (BSA) tools}

Since the impact of building sector activities on the environment and socio-economic contexts was recognised in the 1990s, BSA tools have emerged (Haapio and Viitaniemi 2008) to assess and measure this impact. These integrate the LCA methodology (ISO 14040 2006; ISO 14044 2006) to evaluate the building's performance as a whole through measurable indicators. The first real attempt to approach environmental considerations in buildings was the Building Research Establishment Environmental Assessment Method (BREEAM) (BRE Global 1990), performed by means of a specific tool for buildings. From then on, different organisations have contributed new knowledge through experience, namely the World Green Building Council (WGBC 1990), the International Initiative for Sustainable Building Environment (iiSBE 2004a) (iiSBE 2004a) and the Sustainable Building Alliance (SBA 2009). Within these organisations, several tools have been developed to assess the environmental, social and economic performance of buildings, and have often provided different schemes according to the building's use and type.

A number of studies in the literature have conducted thorough examinations and comparisons of these tools. Among the initial studies, Cole (2005) highlighted their role as market transformation tools and their ability to foster dialogue among a range of stakeholders that go beyond just a design team. After reviewing diverse tools developed in different countries, Kajikawa et al. (2011) noted the complex context in evaluating sustainable green buildings due to the existence of a wide range of systems and diverse perspectives. More recently, Huedo and López-Mesa (2013) carried out an exhaustive classification of a set of BSA tools according to their characteristics and suitability to assist in building design. They also described their advantages and limitations and provided guidelines for the development of a Spanish tool for the selection of sustainable building assemblies. Al-Qawasmi (2018) conducted a detailed examination of the indicator coverage in 11 tools and revealed a deep variation and lack of consensus on the depth and breadth of the coverage of attributes. He found that environmental aspects followed by social ones are the ones with the greatest presence, while the economic dimension reflects a severe lack of representative coverage. 
A set of tools were selected to conduct the study. Bernardi et al. (2017) analysed the most adopted ones according to the number of citations in the Scopus database, number of certified projects and years of development, and found that LEED, BREEAM, CASBEE and SBTool were the ones that were implemented the most. In the framework of this work, BSA tools with a scheme specifically intended for office buildings and applicable to the European context were chosen, which resulted in three BSA tools:

- BREEAM New Construction (BRE Global 1990). This tool was developed in the UK in 1992 as an assessment and certification method based on a rating system, where each of the indicators is given a score according to the importance associated with each of them. Several issues have minimum standards, which means that specific credits or criteria must be achieved. The rating levels for projects are as follows: Unclassified $(<30)$, Pass $(\geq 30)$, Good ( $\geq 45)$, Very good ( $\geq 55)$, Excellent $(\geq 70)$, Outstanding ( $\geq 85)$.

- LEED New Construction and Major Renovation (US GBC 2009). This one was introduced in 2000 in the USA by the US Green Building Council (US GBC) as an assessment and certification method, which later extended its scope internationally. LEED uses a rating system that gives a certain score to the credits that make up the tool, divided into: Certified (40-49), Silver (50-59), Gold (60-79), Platinum ( $\geq 80)$.

- VERDE Equipamiento (GBCe, 2002). The tool was developed in 2002 by GBC Spain, as a response to adapting the SBTool (iiSBE, 2004b) framework to the Spanish context, and is also an assessment and certification system. The methodology used in VERDE differs from the previous ones as it is based on reducing the impact (as a percentage) of the building and its location by implementing design and performance strategies. The scheme awards green leaves to the building according to the impact reduction that is achieved: 0 leaves $(<30 \%), 1$ leaf (30-40\%), 2 leaves (>40-50\%), 3 leaves (>50-60\%), 4 leaves $(>60-80 \%)$ and 5 leaves (>80\%).

\section{Methodology}

The research methodology used to conduct the study is divided into four stages, as depicted in Figure 1 and described below:

- Stage I. Criteria review. Both the EU GPP criteria proposed by the European Commission (2016b) and the BSA sustainability indicators included in three recognised tools, BREEAM, LEED and VERDE, are critically reviewed and crosschecked. This allows GPP and BSA to be compared and crosschecked to identify the gaps in both of them. In addition, the indicators proposed by the BSA tools are clustered in sustainability topics and the weighting conceded to each one is identified, which will enable the tender rating proposal to be shaped for the evaluation process.

- Stage II. Level of fulfilment of GPP criteria by BSA tools. The exhaustive list of GPP criteria is used as a reference to check which BSA indicators cover them. This makes the scope of GPP visible and determines which sustainable construction issues are addressed and which are not, thereby enabling a GPP gap analysis.

- Stage III. Level of fulfilment of BSA criteria by GPP. Contrary to Stage II, BSA criteria are crosschecked with GPP. Two levels of ambition scenarios proposed by GPP (Core and Comprehensive) are applied within the framework of the three BSA tools. By applying the scope of the GPP criteria in each correlated indicator of BSA tools, the score likely to be obtained in the three tools is determined, for the two ambition levels. Then, the score improvement rate that is achieved is calculated.

- Stage IV. Results, based on the following analysis:

- BSA tools rating analysis: an analysis is conducted to determine the improvement in the classification rate achieved in each BSA tool by applying GPP criteria. This makes it possible to calculate the hypothetical rating that can be obtained when 
GPP criteria for both scenarios are applied to an office building, and to then evaluate the level of sustainability of the office building subjected to public tendering.

- GPP weighting proposal: the weighting proposal for the tender evaluation is set, based on the weighting of the BSA indicators, in order to help public authorities award the scores of the offers in the tender during the bidding process.

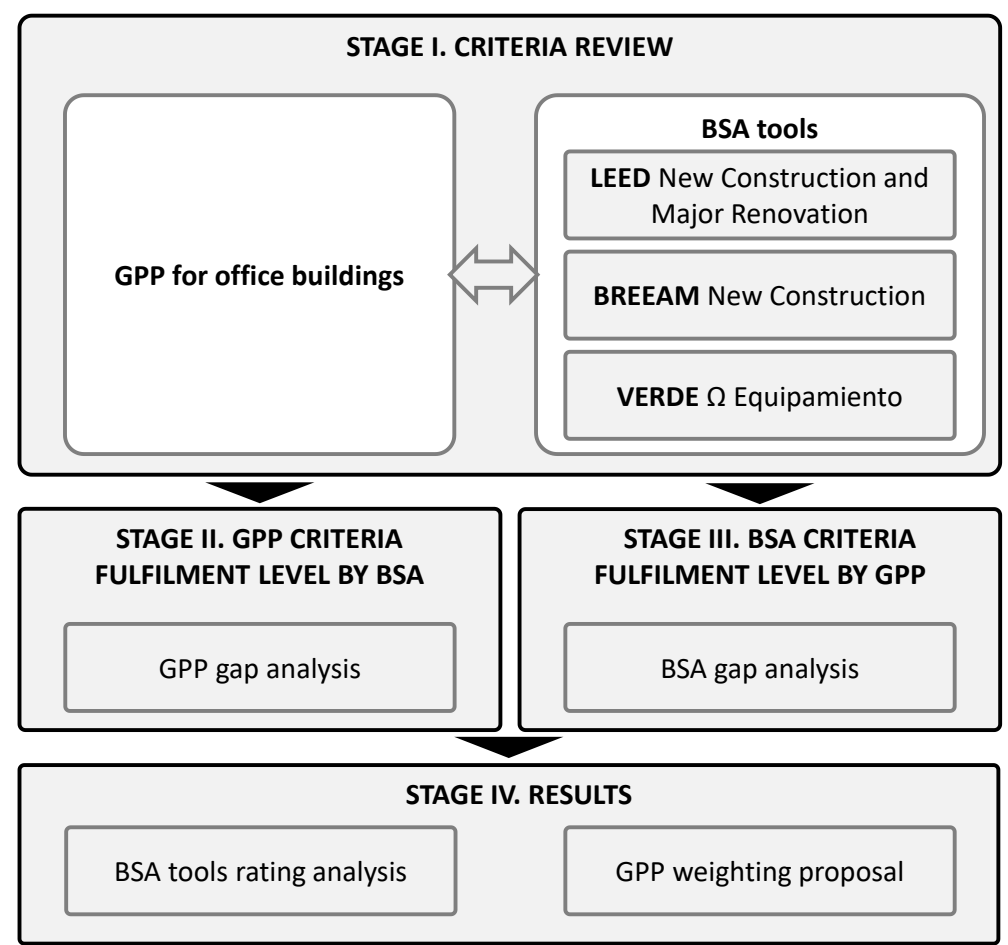

Figure 1. Methodological framework

\section{Findings}

\subsection{Stage I: Criteria review}

\section{GPP criteria for the design, construction and management of office buildings}

As with general EU GPP criteria for other product categories, the EU developed GPP criteria for the "office buildings" category, divided into Selection Criteria (S), Technical Specifications (TS), Award Criteria (A) and Contract Performance clauses (CP). For each set of criteria, there is a choice between two levels of ambition: Core and Comprehensive.

GPP criteria address most of the life cycle of a whole building, including the design, site preparation, construction, servicing and ongoing management stages. These criteria are applicable to both new buildings and the major renovation of existing ones by considering the definition of renovation established by EPBD (2010). GPP criteria cover the following seven stages in the procurement process:

- GPP/A: Selection of the design team and contractors

- GPP/B: Detailed design and performance requirements

- GPP/C: Strip-out, demolition and site preparation works

- GPP/D: Construction of the building or major renovation works

- GPP/E: Fitting energy systems and supplying energy services

- GPP/F: Completion and handover

- GPP/G: Facilities management 
Moreover, different criteria are defined for all the above-cited substages belonging to each stage. The long list of stages, substages and criteria can be found in Table S2 in Supplementary material. The described stages closely relate to the modular structure proposed in EN 15978 (BSI B/558, 2011) to conduct LCA. Figure 2 associates the GPP stages with the related LCA module. As shown, GPP pays special attention to the product, construction and use modules (A-B), while the deconstruction and disposal activities for the building subjected to the tendering (end-of-life (C)) and benefits and loads beyond (D) are not addressed.

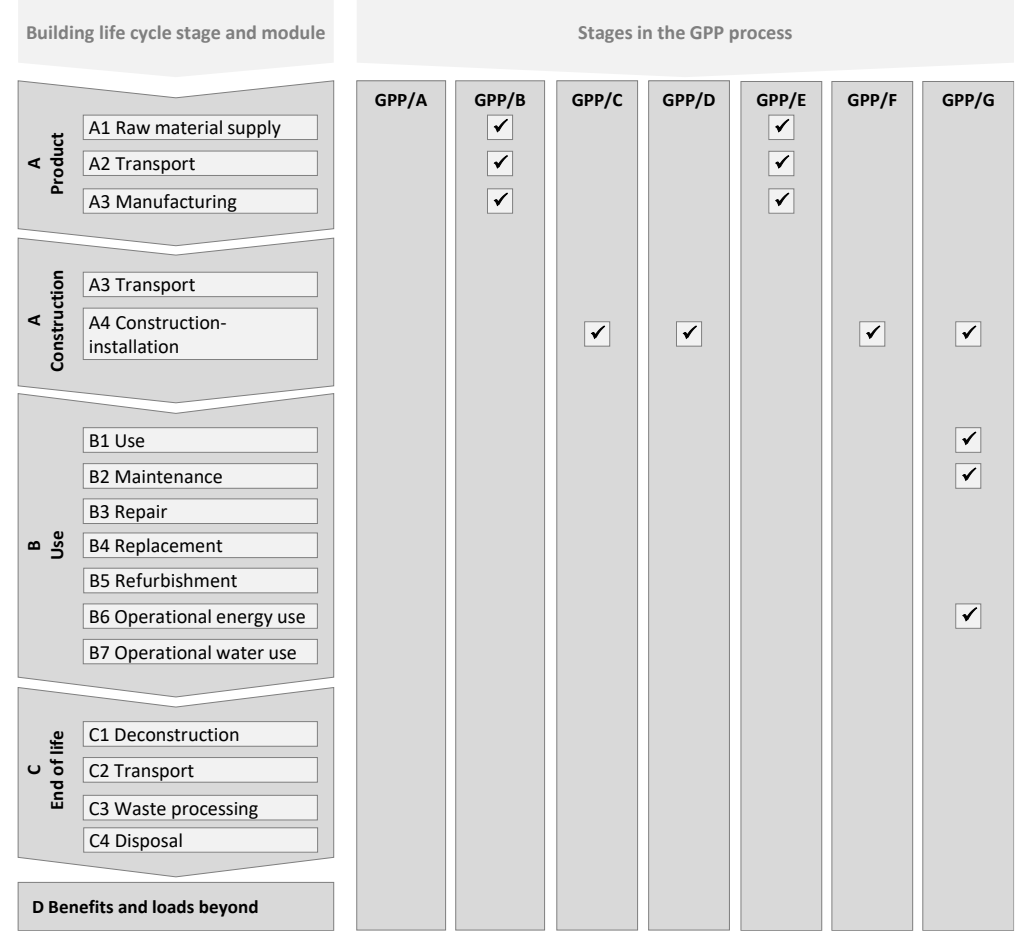

Figure 2. Relationship between the LCA modules and GPP stages

\section{BSA tools criteria}

The indicators considered in each BSA tool are organised in areas that together address different building issues in a comprehensive manner. However, this classification is not common for the three tools analysed here. In order to homogenise the indicator nomenclature used in each one, and according to Braulio-Gonzalo et al. (2015), 14 topics were identified to cluster them. The indicators belonging to each topic and the weight (in \%) that each of them has in each BSA tool are reported in Table 2 (see Tables 4, 5 and 6 for the abbreviation of each indicator for BREEAM, LEED and VERDE, respectively). 
Table 2. Clustering of the building sustainability indicators as topics

\begin{tabular}{|c|c|c|c|c|c|c|}
\hline \multirow[b]{3}{*}{ TOPICS } & \multicolumn{6}{|c|}{ BSA TOOLS } \\
\hline & \multicolumn{2}{|l|}{ BREEAM New Construction } & \multicolumn{2}{|c|}{$\begin{array}{l}\text { LEED New Construction and } \\
\text { Major Renovation }\end{array}$} & \multicolumn{2}{|c|}{ VERDE Equipamiento } \\
\hline & Indicator & Weight & Indicator & Weight & Indicator & Weight \\
\hline Site & USE1 (2.38\%) & $2.38 \%$ & $\begin{array}{l}\text { LT3 }(1.82 \%) \\
\text { LT4 }(4.55 \%) \\
\text { SS4 }(0.91 \%) \\
\text { RP1 }(0.91 \%) \\
\text { RP2 }(0.91 \%) \\
\text { RP3 }(0.91 \%) \\
\text { RP4 }(0.91 \%)\end{array}$ & $10.92 \%$ & PyE07 (2.35\%) & $2.35 \%$ \\
\hline Transport & $\begin{array}{l}\text { TRA1 }(2.18 \%) \\
\text { TRA2 }(1.45 \%) \\
\text { TRA3 }(1.45 \%) \\
\text { TRA4 }(1.47 \%) \\
\text { TRA5 }(1.45 \%)\end{array}$ & $8.00 \%$ & $\begin{array}{l}\text { LT5 }(4.55 \%) \\
\text { LT6 }(0.91 \%) \\
\text { LT7 }(0.91 \%) \\
\text { LT8 }(0.91 \%)\end{array}$ & $7.28 \%$ & $\begin{array}{l}\text { PyEO1 }(2.21 \%) \\
\text { PyEO2 }(2.21 \%) \\
\text { PyEO3 }(2.21 \%)\end{array}$ & $7.80 \%$ \\
\hline $\begin{array}{l}\text { Nature and } \\
\text { biodiversity }\end{array}$ & $\begin{array}{l}\text { SyB7 }(1.00 \%) \\
\text { USE2 }(1.58 \%) \\
\text { USE4 }(2.38 \%) \\
\text { USE5 }(1.58 \%) \\
\text { USE7 }(1.58 \%)\end{array}$ & $8.12 \%$ & $\begin{array}{l}\text { LT2 (0.91\%) } \\
\text { SS3 (1.82\%) }\end{array}$ & $2.73 \%$ & PyE06 (2.21\%) & $2.21 \%$ \\
\hline Energy & $\begin{array}{l}\text { ENE1 ( } 11.74 \% \text {, Pre-requisite) } \\
\text { ENE2 (0.78\%, Pre-requisite) } \\
\text { ENE4 ( } 1.57 \%, \text { Pre-requisite) } \\
\text { ENE6 }(1.57 \%) \\
\text { ENE8 }(1.57 \%)\end{array}$ & $17.23 \%$ & $\begin{array}{l}\text { SS6 (1.82\%) } \\
\text { EA1 (Pre-requisite) } \\
\text { EA2 (Pre-requisite) } \\
\text { EA3 (Pre-requisite) } \\
\text { EA5 }(5.44 \%) \\
\text { EA6 }(16.35 \%) \\
\text { EA7 }(0.91 \%) \\
\text { EA8 }(1.82 \%) \\
\text { EA9 }(2.73 \%) \\
\text { EA11 }(1.82 \%) \\
\end{array}$ & $30.89 \%$ & $\begin{array}{l}\text { PyE04 }(1.17 \%) \\
\text { PyE08 }(1.66 \%) \\
\text { EyA01 }(8.52 \%) \\
\text { EyA02 }(5.05 \%) \\
\text { EyA03 }(3.15 \%) \\
\text { EyA04 }(1.42 \%)\end{array}$ & $19.80 \%$ \\
\hline Water & $\begin{array}{l}\text { SyB4 (1.00\%, Pre-requisite) } \\
\text { SYB8 }(1.00 \%) \\
\text { AG1 }(5.83 \% \text {, Pre-requisite) } \\
\text { AG2 }(1.17 \% \text {, Pre-requisite) } \\
\text { AG3 }(2.33 \%) \\
\text { AG4 }(1.17 \%)\end{array}$ & $12.50 \%$ & $\begin{array}{l}\text { SS5 }(2.72 \%) \\
\text { WE1 (Pre-requisite) } \\
\text { WE2 (Pre-requisite) } \\
\text { WE3 (Pre-requisite) } \\
\text { WE4 }(1.82 \%) \\
\text { WE5 }(5.44 \%) \\
\text { WE6 }(1.82 \%) \\
\text { WE7 }(0.91 \%)\end{array}$ & $12.71 \%$ & $\begin{array}{l}\text { RN01 (3.15\%) } \\
\text { RN02 (1.89\%) } \\
\text { RN04 (1.89\%) }\end{array}$ & $6.93 \%$ \\
\hline Materials & $\begin{array}{l}\text { MAT1 }(6.55 \%) \\
\text { MAT3 }(3.27 \% \text {, Pre-requisite) } \\
\text { MAT4 }(1.09 \%) \\
\text { MAT5 }(1.09 \%) \\
\text { RSD2 }(1.40 \%)\end{array}$ & $13.40 \%$ & $\begin{array}{l}\text { MR1 (Pre-requisite) } \\
\text { MR3 }(4.55 \%) \\
\text { MR4 }(1.82 \%) \\
\text { MR5 }(1.82 \%) \\
\text { MR6 }(1.82 \%) \\
\end{array}$ & $10.01 \%$ & $\begin{array}{l}\text { RN05 (1.58\%) } \\
\text { RN06 (1.26\%) } \\
\text { RN07 (2.52\%) } \\
\text { RN10 (6.95\%) } \\
\text { RN11 (2.52\%) }\end{array}$ & $14.83 \%$ \\
\hline Waste & $\begin{array}{l}\text { RSD1 (4.20\%, Pre-requisite) } \\
\text { RSD3 (1.40\%, Pre-requisite) }\end{array}$ & $5.60 \%$ & $\begin{array}{l}\text { MR2 (Pre-requisite) } \\
\text { MR7 }(1.82 \%)\end{array}$ & $1.82 \%$ & $\begin{array}{l}\text { PyE05 (1.25\%) } \\
\text { RN08 (1.58\%) } \\
\text { RN09 (1.26\%) } \\
\end{array}$ & $4.09 \%$ \\
\hline Pollution & $\begin{array}{l}\text { CONT1 }(2.19 \%) \\
\text { CONT2 }(2.19 \%) \\
\text { CONT3 }(3.65 \%) \\
\text { CONT4 }(0.73 \%) \\
\text { CONT5 }(0.73 \%) \\
\end{array}$ & $9.50 \%$ & $\begin{array}{l}\text { SS1 (Pre-requisite) } \\
\text { SS2 }(0.91 \%) \\
\text { SS7 }(0.91 \%) \\
\text { EA4 (Pre-requisite) } \\
\text { EA10 }(0.91 \%) \\
\end{array}$ & $2.73 \%$ & $\begin{array}{l}\text { PyE09 }(1.25 \%) \\
\text { EyA05 }(2.52 \%)\end{array}$ & $3.77 \%$ \\
\hline $\begin{array}{l}\text { Living } \\
\text { environment }\end{array}$ & $\begin{array}{l}\text { SyB1 (3.00\%, Pre-requisite) } \\
\text { SyB2 }(3.00 \%) \\
\text { SyB3 }(2.00 \%) \\
\text { SyB5 }(2.00 \%) \\
\text { ENE3 }(0.78 \%)\end{array}$ & $10.78 \%$ & $\begin{array}{l}\text { EQ1 (Pre-requisite) } \\
\text { EQ2 (Pre-requisite) } \\
\text { EQ3 }(1.82 \%) \\
\text { EQ4 }(2.72 \%) \\
\text { EQ5 }(0.91 \%) \\
\text { EQ6 }(1.82 \%) \\
\text { EQ7 }(0.91 \%) \\
\text { EQ8 }(1.82 \%) \\
\text { EQ9 }(2.72 \%) \\
\text { EQ10 }(0.91 \%) \\
\text { EQ11 }(0.91 \%) \\
\end{array}$ & $14.54 \%$ & $\begin{array}{l}\text { CAI01 }(3.15 \%) \\
\text { CAI02 }(3.15 \%) \\
\text { CAI03 }(5.05 \%) \\
\text { CAI04 }(3.15 \%) \\
\text { CAI05 }(4.42 \%)\end{array}$ & $18.92 \%$ \\
\hline Social & GST4 (2.30\%, Pre-requisite) & $2.30 \%$ & & $0.00 \%$ & $\begin{array}{l}\text { ASE01 }(2.84 \%) \\
\text { ASE02 }(1.89 \%) \\
\text { CC07 }(1.89 \%) \\
\end{array}$ & $6.62 \%$ \\
\hline Economic & GST5 (1.73\%) & $1.73 \%$ & & $0.00 \%$ & & $0 \%$ \\
\hline $\begin{array}{l}\text { Design and } \\
\text { efficiency }\end{array}$ & SyB6 (1.00\%) & $1.00 \%$ & $\begin{array}{l}\text { Integrative process } \\
(0.91 \%)\end{array}$ & $0.91 \%$ & $\begin{array}{l}\text { CC01 }(1.89 \%) \\
\text { CC03 }(1.26 \%) \\
\text { CC04 }(2.27 \%) \\
\text { CC05 }(1.89) \\
\end{array}$ & $7.31 \%$ \\
\hline Management & $\begin{array}{l}\text { GST1 (3.45\%, Pre-requisite) } \\
\text { GST2 (1.15\%, Pre-requisite) } \\
\text { GST3 }(2.88 \%)\end{array}$ & $7.48 \%$ & & $0.00 \%$ & $\begin{array}{l}\operatorname{CCO2}(3.48 \%) \\
\operatorname{CCO6}(1.89 \%)\end{array}$ & $5.37 \%$ \\
\hline Innovation & INN (10\%) & $10 \%$ & $\begin{array}{l}\text { IN1 (4.55\%) } \\
\text { IN2 (0.91\%) }\end{array}$ & $5.46 \%$ & & $0 \%$ \\
\hline
\end{tabular}


Figure 3 summarises the weight of each topic in the three tools and, as depicted, a fairly high level of agreement is observed. The Energy, Living environment, Materials, Water and Transport topics, in that order, are the ones that most importance is attached to as, obviously, impacts on them depend directly on the building's design, characteristics and performance. Others, such as Site and Nature and biodiversity, encompass fewer opportunities to minimise the whole impact as they are more related to the building's surroundings. It is worth noting that Social and Economic topics are less covered, and compromise the sustainability balance. LEED has no credits related to these two aspects, and VERDE does not include economic issues. More importance should be attached to Management in BSA tools, as the completion and handover of a building and aftercare activities are essential to maintain optimum performance levels in the building's use stage. In fact GPP criteria robustly consider this stage of the building (see Table 3). However, only VERDE and BREEAM include a few Management indicators. Finally, Innovation is addressed by LEED and BREEAM, but not by VERDE, which should also be boosted more intensively to accomplish innovative public procurement.

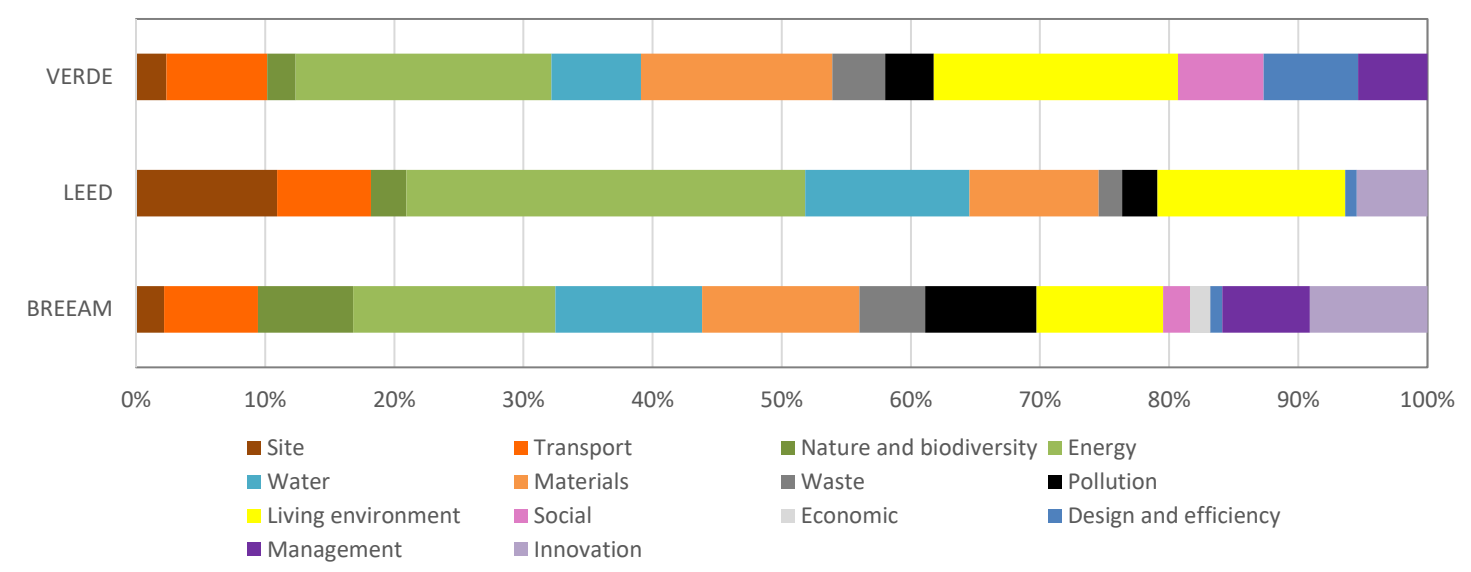

Figure 3. Weight of building topics assumed by the BSA tools analysed

\subsection{Stage II: the level of fulfilment of GPP criteria by BSA tools}

An in-depth review of the sustainability indicators included in the BSA tools VERDE Equipamiento, BREEAM New Construction and LEED New Construction and Major Renovations was conducted and tested with the GPP criteria. This comparison made it possible to identify which GPP criteria are covered by the BSA tools and which are not, whilst also allowing the GPP gap to be analysed. Table 3 presents a long list of the GPP criteria included in each stage, the type of criteria to which they correspond, the level of ambition (Core (Cr) or Comprehensive (Cp)) according to GPP requirements, whether the criterion is linked to another or if it is incompatible, whether it provides guidelines on granting points for award criteria and, finally, whether BSA tools take the criteria into consideration. Four types of GPP criteria are identified according to the Green Public Procurement Handbook (European Commission 2016a).

- Selection criteria (S): specific competence linked to environmental aspects of the design team and contractors.

- Technical specifications (TS): characteristics of the work, supply or service that describe the contract to the market, and provide measurable requirements. They constitute minimum compliance criteria.

- Award criteria (A): additional, not mandatory, environmental performance characteristics that go beyond the minimum requirements. 
- Contract performance clauses (CP): specifications as to how work must be carried out.

Several findings are depicted in Table 3 below. Most GPP criteria correspond to Technical Specifications and are included in the tender document as minimum requirements. Award criteria are fewer in number and are frequently disaggregated into two levels of demand: Core and Comprehensive. Contract performance clauses are integrated in stages D, F and G of the GPP, and are related to the construction of a building, its handover and management. The Selection criteria are covered by integrating into the project an accredited assessor certified by the developer of each BSA tool. Regarding the correspondence between BSA tools and the 69 GPP criteria, in quantitative terms VERDE is related to 44 criteria, BREEAM to 41 and LEED to 38. It can thus be stated that a good level of relationship exists.

Table 3. Test of the GPP criteria being fulfilled by BSA tools

\begin{tabular}{|c|c|c|c|c|c|c|c|c|c|c|c|}
\hline GPP STAGE/Substages/Criteria & 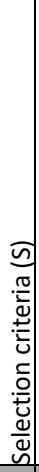 & 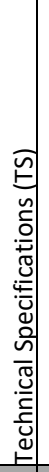 & 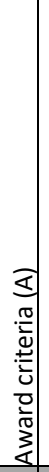 & 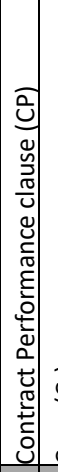 & 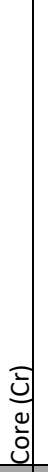 & 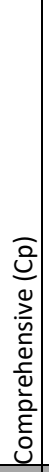 & 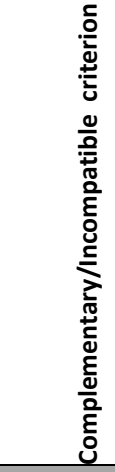 & 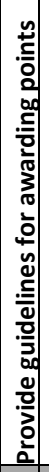 & 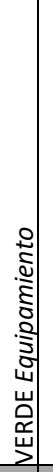 & 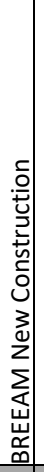 & 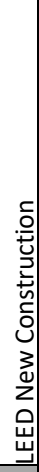 \\
\hline \multicolumn{12}{|l|}{ GPP/A. SELECTION OF THE DESIGN TEAM AND CONTRACTORS } \\
\hline GPP/A1. Competences of the project manager & $\bullet$ & & & & $\bullet$ & $\bullet$ & & & & & $\bullet$ \\
\hline GPP/A2. Competences of the design team & $\bullet$ & & & & $\bullet$ & $\bullet$ & & & $\bullet$ & $\bullet$ & $\bullet$ \\
\hline $\begin{array}{l}\text { GPP/A3. Competences of the main construction contractor and } \\
\text { specialist contractors }\end{array}$ & $\bullet$ & & & & $\bullet$ & $\bullet$ & & & & & $\bullet$ \\
\hline GPP/A4. Competences of DBO contractors and property developers & $\bullet$ & & & & $\bullet$ & $\bullet$ & & & & & $\bullet$ \\
\hline \multicolumn{12}{|l|}{ GPP/B. DETAILED DESIGN AND PERFORMANCE REQUIREMENTS } \\
\hline \multicolumn{12}{|l|}{ GPP/B1. Minimum energy performance } \\
\hline GPP/B1.1. Minimum class of Energy performance Certificate (EPC) & & $\bullet$ & & & $\bullet$ & $\bullet$ & & & $\bullet$ & $\bullet$ & $\bullet$ \\
\hline GPP/B1.2. Cost optimum primary energy demand $\left(\mathrm{kWh} / \mathrm{m}^{2}\right)$ & & $\bullet$ & & & $\bullet$ & & & & & & \\
\hline GPP/B1.3. Dynamic thermal simulation model & & $\bullet$ & & & & $\bullet$ & & & $\bullet$ & $\bullet$ & $\bullet$ \\
\hline GPP/B11.1. Further performance improvements & & & $\bullet$ & & $\bullet$ & & B1.1 & $\bullet$ & $\bullet$ & $\bullet$ & $\bullet$ \\
\hline GPP/B11.2. Design for Near-Zero Energy Buildings (NZEB) & & & $\bullet$ & & & $\bullet$ & B1.1 & $\bullet$ & & $\bullet$ & \\
\hline \multicolumn{12}{|l|}{ GPP/B2. Lighting control systems } \\
\hline GPP/B2.1. Lamps and lighting design & & $\bullet$ & & & $\bullet$ & $\bullet$ & & & $\bullet$ & $\bullet$ & $\bullet$ \\
\hline GPP/B2.2. Fitting occupancy sensors & & $\bullet$ & & & $\bullet$ & $\bullet$ & & & & & $\bullet$ \\
\hline GPP/B2.3. Occupiers able to control lighting systems in zones & & $\bullet$ & & & $\bullet$ & $\bullet$ & & & $\bullet$ & & $\bullet$ \\
\hline \multicolumn{12}{|l|}{ GPP/B3. Building energy management system (BEMS) } \\
\hline GPP/B3.1. Fitting a BEMS & & $\bullet$ & & & $\bullet$ & $\bullet$ & & & $\bullet$ & $\bullet$ & $\bullet$ \\
\hline GPP/B3.2. Easy user interface providing information & & $\bullet$ & & & $\bullet$ & $\bullet$ & & & $\bullet$ & $\bullet$ & \\
\hline GPP/B3.3. Occupants able to adjust comfort conditions in zones & & $\bullet$ & & & & $\bullet$ & & & $\bullet$ & $\bullet$ & \\
\hline $\begin{array}{l}\text { GPP/B3.4. Technical systems (HVAC, lighting, etc.) controlled by } \\
\text { occupants }\end{array}$ & & $\bullet$ & & & $\bullet$ & $\bullet$ & & & $\bullet$ & $\bullet$ & \\
\hline GPP/B3.5. The BEMS offers additional capabilities & & $\bullet$ & & & & $\bullet$ & & & $\bullet$ & & \\
\hline \multicolumn{12}{|l|}{ GPP/B4. Low or zero carbon energy sources } \\
\hline GPP/B4.1. Connexion of the building to renewable energy systems & & $\bullet$ & & & $\bullet$ & & & & & $\bullet$ & $\bullet$ \\
\hline GPP/B4.2. A minimum of $10 \%$ primary energy with renewables & & $\bullet$ & & & & $\bullet$ & & & & & $\bullet$ \\
\hline GPP/B13. Additional primary energy from renewables & & & $\bullet$ & & & $\bullet$ & & $\bullet$ & & & $\bullet$ \\
\hline \multicolumn{12}{|l|}{ GPP/B5. Staff travel plan and infrastructure } \\
\hline GPP/B5.1. Staff travel plan to reduce commuting & & $\bullet$ & & & $\bullet$ & $\bullet$ & & & $\bullet$ & $\bullet$ & $\bullet$ \\
\hline GPP/B5.2. Accessible bicycle storage & & $\bullet$ & & & $\bullet$ & $\bullet$ & & & $\bullet$ & $\bullet$ & $\bullet$ \\
\hline GPP/B5.3. Electric recharching points for electric vehicles and e-bikes & & $\bullet$ & & & & $\bullet$ & & & $\bullet$ & $\bullet$ & $\bullet$ \\
\hline \multicolumn{12}{|l|}{ GPP/B6. Recyclable waste storage } \\
\hline GPP/B6.1. Waste storage space for segregation & & $\bullet$ & & & $\bullet$ & $\bullet$ & & & $\bullet$ & $\bullet$ & $\bullet$ \\
\hline
\end{tabular}




\begin{tabular}{|c|c|c|c|c|c|c|c|c|c|c|}
\hline \multicolumn{11}{|l|}{ GPP/B7. Water saving installations } \\
\hline GPP/B7.1. Water-efficient fittings in sanitary and kitchen facilities & $\bullet$ & $\bullet$ & & $\bullet$ & $\bullet$ & & & $\bullet$ & $\bullet$ & $\bullet$ \\
\hline \multicolumn{11}{|l|}{ GPP/B8. Thermal comfort conditions } \\
\hline GPP/B8.1. Indoor temperature in accordance with EN 15251 & $\bullet$ & & & $\bullet$ & $\bullet$ & & & $\bullet$ & • & $\bullet$ \\
\hline GPP/B8.2. Dynamic thermal simulation modelling & $\bullet$ & & & & $\bullet$ & & & & $\bullet$ & \\
\hline \multicolumn{11}{|l|}{ GPP/B9. Daylighting and glare control } \\
\hline GPP/B9.1. Daylight Factor & $\bullet$ & & & $\bullet$ & $\bullet$ & & & $\bullet$ & $\bullet$ & $\bullet$ \\
\hline GPP/B9.2. Control measures for glare & $\bullet$ & & & & & & & $\bullet$ & $\bullet$ & $\bullet$ \\
\hline GPP/B9.3. Dynamic modelling & $\bullet$ & & & & $\bullet$ & & & $\bullet$ & $\bullet$ & $\bullet$ \\
\hline \multicolumn{11}{|l|}{ GPP/B10. Ventilation and air quality } \\
\hline GPP/B10.1. Indoor air quality according to EN 15251 & $\bullet$ & & & $\bullet$ & $\bullet$ & & & & & \\
\hline GPP/B10.2. Ventilation system filters according to EN 13779 & $\bullet$ & & & $\bullet$ & $\bullet$ & & & & • & \\
\hline GPP/B10.3. No air intake positioned on facades facing busy roads & $\bullet$ & & & $\bullet$ & & & & & $\bullet$ & $\bullet$ \\
\hline GPP/B10.4. Air intakes located $20 \mathrm{~m}$ from poor air quality sources & $\bullet$ & & & & $\bullet$ & & & & $\bullet$ & $\bullet$ \\
\hline \multicolumn{11}{|l|}{ GPP/B12. Building life cycle GWP } \\
\hline GPP/B12.1. Low GWP (global warming potential) & & $\bullet$ & & $\bullet$ & $\bullet$ & B14.1 & & $\bullet$ & $\bullet$ & \\
\hline \multicolumn{11}{|l|}{ GPP/B14. Performance of the main building elements (EPD or LCA) } \\
\hline GPP/B14.1. EPDs (Environmental Product Declarations) & & $\bullet$ & & & & B11.1 & $\bullet$ & $\bullet$ & • & $\bullet$ \\
\hline GPP/B14.2. LCA (Life Cycle Assessment) & & $\bullet$ & & & & B11.1 & $\bullet$ & $\bullet$ & $\bullet$ & $\bullet$ \\
\hline \multicolumn{11}{|l|}{ GPP/B15. Incorporation of recycled content in concrete and masonry } \\
\hline GPP/B15.1. $15 \%$ of recycled content & & $\bullet$ & & $\bullet$ & & B16,B14.1 & $\bullet$ & $\bullet$ & $\bullet$ & \\
\hline GPP/B15.2. $30 \%$ of recycled content & & $\bullet$ & & & $\bullet$ & & $\bullet$ & $\bullet$ & • & \\
\hline \multicolumn{11}{|l|}{$\begin{array}{l}\text { GPP/B16. Performance requirements for } \mathrm{CO} 2 \text { emissions from } \\
\text { transporting aggregates }\end{array}$} \\
\hline GPP/B16.1. Reduction in the CO2e emission/tonne of aggregates & & $\bullet$ & & $\bullet$ & $\bullet$ & B14.1,B14.2 & $\bullet$ & & & \\
\hline \multicolumn{11}{|l|}{ GPP/C. STRIP-OUT, DEMOLITION AND SITE PREPARATION WORKS } \\
\hline \multicolumn{11}{|l|}{ GPP/C1. Demolition waste audit and management plan } \\
\hline GPP/C1.1. Reuse of $55 \%$ of non-hazardous demolition waste & $\bullet$ & & & $\bullet$ & & & & $\bullet$ & $\bullet$ & \\
\hline GPP/C1.2. Reuse of $80 \%$ of non-hazardous demolition waste & $\bullet$ & & & & $\bullet$ & & & $\bullet$ & $\bullet$ & \\
\hline GPP/C1.3. Pre-demolition/strip-out audit & $\bullet$ & & & $\bullet$ & $\bullet$ & & & $\bullet$ & • & \\
\hline \multicolumn{11}{|l|}{$\begin{array}{l}\text { GPP/D. CONSTRUCTION THE BUILDING OR MAJOR RENOVATION } \\
\text { WORKS }\end{array}$} \\
\hline \multicolumn{11}{|l|}{ GPP/D1. Sourcing of legal timber by the lead construction contractor } \\
\hline GPP/D1.1 Legally harvested timber & $\bullet$ & & $\bullet$ & $\bullet$ & $\bullet$ & & $\bullet$ & $\bullet$ & • & \\
\hline \multicolumn{11}{|l|}{ GPP/D2. Fitting and commissioning building energy systems } \\
\hline GPP/D2.1. Functional performance testing routine & $\bullet$ & & $\bullet$ & $\bullet$ & $\bullet$ & & & $\bullet$ & & \\
\hline \multicolumn{11}{|l|}{ GPP/D3. Site waste management } \\
\hline GPP/D3.1. Waste arisings $\leq 11$ tonnes per $100 \mathrm{~m}^{2}$ & $\bullet$ & & $\bullet$ & $\bullet$ & & & & $\bullet$ & & $\bullet$ \\
\hline GPP/D3.2. Waste arisings $\leq 7$ tonnes per $100 \mathrm{~m}^{2}$ & $\bullet$ & & • & & $\bullet$ & & & $\bullet$ & & $\bullet$ \\
\hline GPP/D3.3. Waste management plan & $\bullet$ & & $\bullet$ & $\bullet$ & & & & $\bullet$ & $\bullet$ & $\bullet$ \\
\hline GPP/D3.4. Identifying waste prevention opportunities & $\bullet$ & & $\bullet$ & & $\bullet$ & & & $\bullet$ & & $\bullet$ \\
\hline \multicolumn{11}{|l|}{ GPP/D4. Selecting fit-out materials and finishes } \\
\hline GPP/D4.1. Compliance emission limits in Table E of GPP Criteria & $\bullet$ & & & $\bullet$ & & & & $\bullet$ & $\bullet$ & $\bullet$ \\
\hline GPP/D4.2. Compliance emission limits in Table G of GPP Criteria & $\bullet$ & & & & $\bullet$ & & & $\bullet$ & $\bullet$ & $\bullet$ \\
\hline \multicolumn{11}{|l|}{ GPP/D5. Incorporating recycled content } \\
\hline GPP/D5.1. Verification of recycled content & & & $\bullet$ & $\bullet$ & $\bullet$ & & & $\bullet$ & $\bullet$ & \\
\hline GPP/E. FITTING ENERGY SYSTEMS AND SUPPLYING ENERGY SERVI & & & & & & & & & & \\
\hline GPP/E1. Heating systems, including combined heat and power ( $\mathrm{Cr}$ & & & & & & & & & & \\
\hline GPP/E1.1. Meeting GPP Core Criteria on 'Water-based Heaters' & $\bullet$ & & & $\bullet$ & & & & & & \\
\hline $\begin{array}{l}\text { GPP/E1.2. Meeting GPP Comprehensive Criteria on 'Water-based } \\
\text { Heaters' }\end{array}$ & $\bullet$ & & & & $\bullet$ & & & & & \\
\hline GPP/F. COMPLETION AND HANDOVER & & & & & & & & & & \\
\hline GPP/F1. Quality of the completed building fabric & & & & & & & & & & \\
\hline GPP/F1.1. Air tightness $4 \mathrm{~m} 3 /\left(\mathrm{h} \cdot \mathrm{m}^{2}\right)$ & $\bullet$ & & $\bullet$ & $\bullet$ & & & & $\bullet$ & $\bullet$ & $\bullet$ \\
\hline GPP/F1.2. Air tightness $2 \mathrm{~m} 3 /\left(\mathrm{h} \cdot \mathrm{m}^{2}\right)$ & $\bullet$ & & $\bullet$ & & $\bullet$ & & & $\bullet$ & $\bullet$ & $\bullet$ \\
\hline $\begin{array}{l}\text { GPP/F2. Installation and commission of low or zero carbon energ) } \\
\text { sources }\end{array}$ & & & & & & & & & & \\
\hline GPP/F2.1. Aftercare service & & $\bullet$ & & $\bullet$ & $\bullet$ & & & & & \\
\hline GPP/F2.2. Low or zero carbon energy systems commissioning & & & $\bullet$ & $\bullet$ & $\bullet$ & B4 & & & & \\
\hline GPP/F4. Lighting control systems & & & & & & & & & & \\
\hline
\end{tabular}




\begin{tabular}{|c|c|c|c|c|c|c|c|c|}
\hline GPP/F4.1. GPP criteria for indoor lighting commissioning & & $\bullet$ & $\bullet$ & $\bullet$ & & $\bullet$ & & $\bullet$ \\
\hline \multicolumn{9}{|l|}{ GPP/F5. Building energy management system (BEMS) } \\
\hline GPP/F5.1. BEMS commissioning & & $\bullet$ & $\bullet$ & $\bullet$ & & $\bullet$ & & $\bullet$ \\
\hline \multicolumn{9}{|l|}{ GPP/F6. Recyclable waste storage } \\
\hline GPP/F6.1. Storage space for waste segregation & & $\bullet$ & $\bullet$ & $\bullet$ & B6 & $\bullet$ & $\bullet$ & $\bullet$ \\
\hline \multicolumn{9}{|l|}{ GPP/F7. Air quality testing } \\
\hline GPP/F7.1. Air quality testing & & $\bullet$ & & $\bullet$ & D4 & $\bullet$ & & $\bullet$ \\
\hline \multicolumn{9}{|l|}{ GPP/G. FACILITIES MANAGEMENT } \\
\hline \multicolumn{9}{|l|}{ GPP/G1. Building energy management system (BEMS) } \\
\hline GPP/G1.1. BEMS monthly reports & $\bullet$ & & $\bullet$ & & & $\bullet$ & $\bullet$ & $\bullet$ \\
\hline GPP/G1.2. Results per zone and energy saving recommendations & $\bullet$ & & & $\bullet$ & & & $\bullet$ & \\
\hline \multicolumn{9}{|l|}{ GPP/G2. Energy performance contract (EPC) } \\
\hline GPP/G2.1. Energy performance contract agreement & $\bullet$ & & $\bullet$ & $\bullet$ & & & $\bullet$ & $\bullet$ \\
\hline GPP/G2.2. Data verification & & $\bullet$ & $\bullet$ & $\bullet$ & & & $\bullet$ & $\bullet$ \\
\hline \multicolumn{9}{|l|}{ GPP/G3. Waste management system } \\
\hline GPP/G3.1. Systems to segregate waste arisings by occupiers & $\bullet$ & & $\bullet$ & & & & & $\bullet$ \\
\hline GPP/G3.2. Verifying the waste segregation system & $\bullet$ & & & $\bullet$ & & & & $\bullet$ \\
\hline GPP/G3.3. Monitoring and quantification of waste arisings & & $\bullet$ & $\bullet$ & $\bullet$ & & & & $\bullet$ \\
\hline
\end{tabular}

Notes: $\bullet$ correspondence between GPP criteria and characteristics; Strikethrough text means incompatible criteria to be used at the same time when applying GPP

\subsection{Stage III: the level of fulfilment of BSA criteria by GPP}

As seen in the previous section, the set of criteria offered by GPP is closely related to the indicators proposed by BSA tools. In this section, the level of fulfilment that can be achieved in BSA tools by applying GPP criteria is assessed. For this purpose, a hypothetical office building is taken as a reference, regardless of its BSA score (if applicable), and each GPP criterion is implemented within the context of the three tools to calculate the improvement rate obtained by VERDE and the number of credits obtained with BREEAM and LEED. This allows the determination of the BSA improvement rate that results from implementing GPP criteria. Two scenarios with different levels of ambition were considered:

- Standard scenario: comprising the selection criteria and technical specifications. It refers to the minimum requirements that should be included in the tender, and involves both core and comprehensive criteria.

- Ambitious scenario: comprising the award criteria. It implies more ambitious requirements to achieve more innovative performance.

Each requirement established by each GPP criteria is applied to the BSA tools framework. In VERDE, the score is expressed as a percentage of improvement, while the score obtained in BREEAM and LEED is given as a number of credits that are later transformed into a percentage as part of this study to allow a comparison among tools.

Tables 4, 5 and 6 present the results of applying both GPP scenarios in VERDE, BREEAM and LEED, respectively. These tables relate the sustainability indicators of BSA tools to GPP criteria, matching them both. Sustainability indicators are placed in the first column. The number of credits available or the percentage is given for each indicator, as is a minimum standard (BREEAM) or a pre-requisite (LEED) to achieve a certain rate class. Next come details of which specific GPP criterion considers (but may not cover) each BSA indicator and when, and also whether a suggestion for award points exists. Finally, both the standard (core and comprehensive criteria) and ambitious (award criteria) GPP scenarios are applied, and the score obtained in the tool is determined. 
Table 4. Calculating the improvement rate by applying GPP in BREEAM New Construction

\begin{tabular}{|c|c|c|c|c|c|c|c|c|c|c|c|}
\hline Area/Indicator & 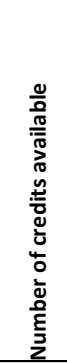 & 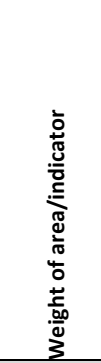 & 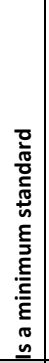 & 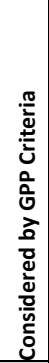 & 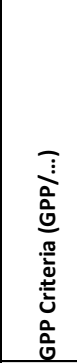 & 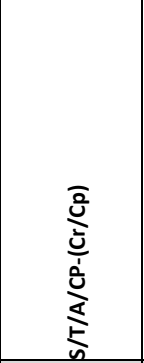 & 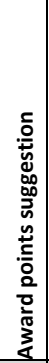 & 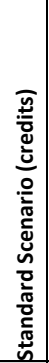 & 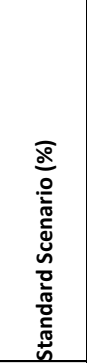 & 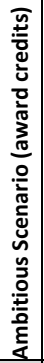 & 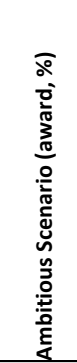 \\
\hline Management (GST) & & $11.50 \%$ & & & & & & 5 & $2.88 \%$ & 5 & $2.88 \%$ \\
\hline \multirow[t]{3}{*}{ GST1 Aftercare } & \multirow[t]{3}{*}{$6+1$} & \multirow[t]{3}{*}{$3.45 \%$} & \multirow[t]{3}{*}{$\bullet$} & \multirow[t]{3}{*}{$\bullet$} & F1.1 & $\mathrm{T} / \mathrm{CP}(\mathrm{Cr})$ & $\bullet$ & \multirow[t]{3}{*}{3} & \multirow[t]{3}{*}{$1.73 \%$} & \multirow[t]{3}{*}{3} & \multirow[t]{3}{*}{$1.73 \%$} \\
\hline & & & & & F1.2 & $\mathrm{T} / \mathrm{CP}(\mathrm{Cp})$ & & & & & \\
\hline & & & & & G1.1 & $\mathrm{T}(\mathrm{Cr})$ & & & & & \\
\hline \multirow{2}{*}{ GST3 Sustainable construction practices } & \multirow[t]{2}{*}{5} & $2.88 \%$ & & $\bullet$ & D1.1 & $\mathrm{T} / \mathrm{CP}(\mathrm{Cr} / \mathrm{Cp})$ & $\bullet$ & 2 & $1.15 \%$ & 2 & $1.15 \%$ \\
\hline & & & & & D3.3 & $\mathrm{T} / \mathrm{CP}(\mathrm{Cr})$ & $\bullet$ & & & & \\
\hline GST4 Project brief and design & 4 & $2.30 \%$ & & & & & & & & & \\
\hline GST5 Life cycle cost and service life planning & 3 & $1.73 \%$ & & & & & & & & & \\
\hline Health and well-being (SyB) & & $14.00 \%$ & & & & & & 7 & $7.00 \%$ & 7 & $7.00 \%$ \\
\hline SyB1 Visual comfort & 3 & $3.00 \%$ & $\bullet$ & $\bullet$ & $\mathrm{B} 2.1$ & $\mathrm{~T}(\mathrm{Cr} / \mathrm{Cp})$ & $\bullet$ & 3 & $3.00 \%$ & 3 & $3.00 \%$ \\
\hline & & & & & B9.1 & $\mathrm{T}(\mathrm{Cr})$ & & & & & \\
\hline & & & & & B9.2 & $\mathrm{T}(\mathrm{Cr})$ & & & & & \\
\hline & & & & & B9.3 & $\mathrm{T}(\mathrm{Cp})$ & & & & & \\
\hline SyB2 Indoor air quality & $3+2$ & $3.00 \%$ & & $\bullet$ & B10.2 & $\mathrm{T}(\mathrm{Cr} / \mathrm{Cp})$ & $\bullet$ & & & & \\
\hline & & & & & B10.3 & $\mathrm{T}(\mathrm{Cr})$ & & & & & \\
\hline & & & & & \begin{tabular}{|l|l|} 
B10.4 \\
\end{tabular} & $T(C p)$ & & & & & \\
\hline SyB7 Natural risks & 1 & $1.00 \%$ & & & & & & & & & \\
\hline SYB8 Sustainable water treatment in swimming pools & 1 & $1.00 \%$ & & & & & & & & & \\
\hline Energy (ENE) & & $18.00 \%$ & & & & & & 1 & $0.78 \%$ & 1 & $0.78 \%$ \\
\hline ENE1 Reducing energy use and carbon emissions & $15+5$ & $11.74 \%$ & & $\bullet$ & B1.1 & $\mathrm{T}(\mathrm{Cr} / \mathrm{Cp})$ & & 0 & $0.00 \%$ & 0 & $0.00 \%$ \\
\hline & & & & & B1.3 & $\mathrm{T}(\mathrm{Cp})$ & & & & & \\
\hline & & & & & B11.1 & $\mathrm{A}(\mathrm{Cr})$ & & & & & \\
\hline & & & & & B11.2 & $A(C p)$ & & & & & \\
\hline ENE2 Energy monitoring & 1 & $0.78 \%$ & & $\bullet$ & B3.1 & $\mathrm{T}(\mathrm{Cr} / \mathrm{Cp})$ & & 1 & $0.78 \%$ & 1 & $0.78 \%$ \\
\hline & & & & & B3.2 & $\mathrm{T}(\mathrm{Cr} / \mathrm{Cp})$ & & & & & \\
\hline & & & & & B3.3 & $\mathrm{T}(\mathrm{Cp})$ & & & & & \\
\hline & & & & & B3.4 & $\mathrm{T}(\mathrm{Cr} / \mathrm{Cp})$ & & & & & \\
\hline ENE3 External lighting & 1 & $0.78 \%$ & & & & & & & & & \\
\hline ENE4 Low carbon design & 2 & $1.57 \%$ & & $\bullet$ & B4.1 & $\mathrm{T}(\mathrm{Cr})$ & & 0 & $0.00 \%$ & 0 & $0.00 \%$ \\
\hline ENE5 Energy-efficient cold storage & & & & & & & & & & & \\
\hline ENE6 Energy-efficient transportation systems & 2 & $1.57 \%$ & & & & & & & & & \\
\hline ENE7 Energy-efficient laboratory systems & & & & & & & & & & & \\
\hline ENE8 Energy-efficient equipment & 2 & $1.57 \%$ & & & & & & & & & \\
\hline Transport (TRA) & & $8.00 \%$ & & & & & & 7 & $5.08 \%$ & 7 & $5.08 \%$ \\
\hline TRA1 Public transport accessibility & 3 & $2.18 \%$ & & $\bullet$ & B5.1 & $\mathrm{T}(\mathrm{Cr} / \mathrm{Cp})$ & & 3 & $2.18 \%$ & 3 & $2.18 \%$ \\
\hline TRA2 Proximity to amenities & 2 & $1.45 \%$ & & & & & & & & & \\
\hline TRA3 Cycling facilities & 2 & $1.45 \%$ & & $\bullet$ & B5.2 & $\mathrm{T}(\mathrm{Cr} / \mathrm{Cp})$ & & 2 & $1.45 \%$ & 2 & $1.45 \%$ \\
\hline & & & & & B5.3 & $T(C p)$ & & & & & \\
\hline TRA4 Maximum car parking capacity & 2 & & & & & & & & & & \\
\hline TRA5 Travel plan & 2 & $1.45 \%$ & & $\bullet$ & B5.1 & $\mathrm{T}(\mathrm{Cr} / \mathrm{Cp})$ & & 2 & $1.45 \%$ & 2 & $1.45 \%$ \\
\hline
\end{tabular}




\begin{tabular}{|c|c|c|c|c|c|c|c|c|c|}
\hline Waste (RSD) & & $7.00 \%$ & & & & 3 & $4.20 \%$ & 4 & $5.60 \%$ \\
\hline \multirow[t]{3}{*}{ RSD1 Construction waste management } & \multirow[t]{3}{*}{$3+1$} & \multirow[t]{3}{*}{$4.20 \%$} & \multirow[t]{3}{*}{$\bullet$} & C1.1 & $\mathrm{T}(\mathrm{Cr})$ & \multirow[t]{3}{*}{2} & \multirow[t]{3}{*}{$2.80 \%$} & \multirow[t]{3}{*}{2} & \multirow[t]{3}{*}{$2.80 \%$} \\
\hline & & & & C1.2 & $T(C p)$ & & & & \\
\hline & & & & C1.3 & $\mathrm{T}(\mathrm{Cr} / \mathrm{Cp})$ & & & & \\
\hline \multirow[t]{3}{*}{ RSD2 Recycled aggregates } & \multirow[t]{3}{*}{$1+1$} & \multirow[t]{3}{*}{$1.40 \%$} & \multirow[t]{3}{*}{$\bullet$} & B15.1 & $\mathrm{A}(\mathrm{Cr})$ & & & \multirow[t]{3}{*}{1} & \multirow[t]{3}{*}{$1.40 \%$} \\
\hline & & & & $\mathrm{B} 15.2$ & $A(C p)$ & & & & \\
\hline & & & & D5.1 & $\mathrm{CP}(\mathrm{Cr} / \mathrm{Cp})$ & & & & \\
\hline \multirow[t]{2}{*}{ RSD3 Operational waste } & \multirow[t]{2}{*}{1} & \multirow[t]{2}{*}{$1.40 \%$} & \multirow[t]{2}{*}{$\bullet$} & B6.1 & $\mathrm{T}(\mathrm{Cr} / \mathrm{Cp})$ & \multirow[t]{2}{*}{1} & \multirow[t]{2}{*}{$1.40 \%$} & \multirow[t]{2}{*}{1} & \multirow[t]{2}{*}{$1.40 \%$} \\
\hline & & & & F6.1 & $\mathrm{CP}(\mathrm{Cr} / \mathrm{Cp})$ & & & & \\
\hline \multicolumn{10}{|l|}{ RSD4 Speculative floor and ceiling finishes } \\
\hline Land use and ecology (USE) & & $9.50 \%$ & & & & & $0.00 \%$ & & $0.00 \%$ \\
\hline USE1 Site selection & 3 & $2.38 \%$ & & & & & & & \\
\hline $\begin{array}{l}\text { USE4 Ecological value of site and protection of ecological } \\
\text { features }\end{array}$ & 3 & $2.38 \%$ & & & & & & & \\
\hline USE5 Long-term impact on biodiversity & 2 & $1.58 \%$ & & & & & & & \\
\hline USE7 Enhancing site ecology & 2 & $1.58 \%$ & & & & & & & \\
\hline Pollution (CONT) & & $9.50 \%$ & & & & & $0.00 \%$ & & $0.00 \%$ \\
\hline CONT1 Impact of refrigerants & 3 & $2.19 \%$ & & & & & & & \\
\hline CONT2 NOx emissions & 3 & $2.19 \%$ & & & & & & & \\
\hline CONT3 Surface water run-off & 5 & $3.65 \%$ & & & & & & & \\
\hline CONT4 Reducing nighttime light pollution & 1 & $0.73 \%$ & & & & & & & \\
\hline CONT5 Reducing noise pollution & 1 & $0.73 \%$ & & & & & & & \\
\hline Innovation (INN) & & $10.00 \%$ & & & & 1 & $1.00 \%$ & 2 & $2.00 \%$ \\
\hline INN1 Innovation & 10 & $10.00 \%$ & & & & 1 & $1.00 \%$ & 2 & $2.00 \%$ \\
\hline TOTAL & & $110 \%$ & & & & & $24.44 \%$ & & $33.39 \%$ \\
\hline
\end{tabular}

Note: $\bullet$ applicable; o considered, but not met by GPP

In BREEAM New Construction, the standard scenario accounts for $24.44 \%$, while the ambitious scenario accounts for $33.39 \%$. Waste management (RSD), Materials (MAT) and Transport (TRA) are the most covered areas, especially by the ambitious scenario, which allows the score to increase notably. GPP has a medium impact on Health and well-being (SyB), Management (GST) and Water (AG). Energy (ENE) is slightly covered because its respective specifications do not easily match, but energy issues are addressed by both GPP and BSA. Thus GPP does not increase the score in the tool. Land use (USE) and Pollution (CONT) are not covered by GPP and, generally, the same applies to the other tools. The ambitious scenario provides better performance than the standard one in terms of Materials (with the assessment of life cycle impacts by conducting an LCA of the whole building), Waste management (considering the incorporation of recycled aggregates) and Innovation. It should be noted that some of the minimum standards introduced by BREEAM are not met with GPP, which acts as a barrier preventing a class from being achieved in the tool, namely: Stakeholders' involvement (GST4), Water quality and monitoring (SyB4 and AG2) and the Development of low carbon technologies viability plan (ENE4). So even though these are not considered in a tender, project designers and managers should bear in mind such considerations to obtain the BREEAM label. 
Table 5. Calculating the improvement rate by applying GPP in LEED New Construction and Major Renovation

\begin{tabular}{|c|c|c|c|c|c|c|c|c|c|c|c|}
\hline Area/Indicator & 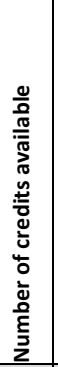 & 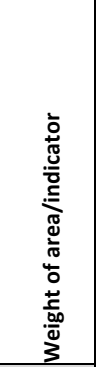 & 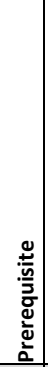 & 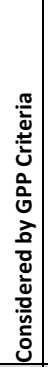 & 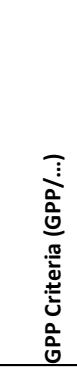 & 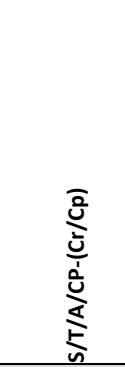 & 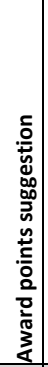 & 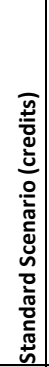 & 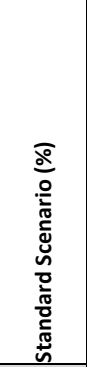 & 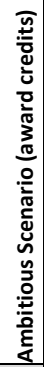 & 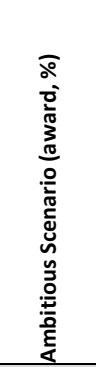 \\
\hline Integrative process & 1 & $0.91 \%$ & & & & & & 0 & $0.00 \%$ & 0 & $0.00 \%$ \\
\hline Location and transportation (LT) & 16 & $14.55 \%$ & & & & & & 6 & $5.45 \%$ & 6 & $5.45 \%$ \\
\hline LT1 LEED for Neighbourhood Development Location & 16 & & & & & & & & & & \\
\hline LT2 Sensitive Land Protection & 1 & & & & & & & & & & \\
\hline LT3 High-Priority Site & 2 & & & & & & & & & & \\
\hline LT4 Surrounding Density and Diverse Uses & 5 & & & & & & & & & & \\
\hline LT5 Access to Quality Transit & 5 & & & $\bullet$ & B5.1 & $\mathrm{T}(\mathrm{Cr} / \mathrm{Cp})$ & $\bullet$ & 5 & & 5 & \\
\hline \multirow[t]{2}{*}{ LT6 Cycling Facilities } & \multirow[t]{2}{*}{1} & & & \multirow[t]{2}{*}{$\bullet$} & B5.2 & $\mathrm{T}(\mathrm{Cr} / \mathrm{Cp})$ & \multirow[t]{2}{*}{$\bullet$} & \multirow[t]{2}{*}{0} & & \multirow[t]{2}{*}{0} & \\
\hline & & & & & B5.3 & $T(C p)$ & & & & & \\
\hline LT7 Small Parking Footprint & 1 & & & & & & & & & & \\
\hline LT8 Green Vehicles & 1 & & & $\bullet$ & B5.2 & $\mathrm{T}(\mathrm{Cr} / \mathrm{Cp})$ & $\bullet$ & 1 & & 1 & \\
\hline Sustainable sites (SS) & 10 & $9.09 \%$ & & & & & & 0 & $0.00 \%$ & 0 & $0.00 \%$ \\
\hline SS1 Construction Activity Pollution Prevention & & & $\circ$ & $\bullet$ & & & & 0 & & 0 & \\
\hline SS2 Site Assessment & 1 & & & & & & & & & & \\
\hline SS3 Site Development - Protect or Restore Habitat & 2 & & & & & & & & & & \\
\hline SS4 Open Space & 1 & & & & & & & & & & \\
\hline SS5 Rainwater Management & 3 & & & & & & & & & & \\
\hline SS6 Reducing Heat Island & 2 & & & & & & & & & & \\
\hline SS7 Reducing Light Pollution & 1 & & & & & & & & & & \\
\hline Water efficiency (WE) & 11 & $10.00 \%$ & & & & & & 0 & $0.00 \%$ & 0 & $0.00 \%$ \\
\hline WE1 Reducing Outdoor Water Use & & & $\circ$ & & & & & & & & \\
\hline WE2 Reducing Indoor Water Use & & & $\circ$ & $\bullet$ & B7.1 & $\mathrm{T} / \mathrm{A}(\mathrm{Cr} / \mathrm{Cp})$ & $\bullet$ & 0 & & 0 & \\
\hline WE3 Building-Level Water Metering & & & $\circ$ & & & & & & & & \\
\hline WE4 Reducing Outdoor Water Use & 2 & & & & & & & & & & \\
\hline WE5 Reducing Indoor Water Use & 6 & & & $\bullet$ & B7.1 & $\mathrm{T} / \mathrm{A}(\mathrm{Cr} / \mathrm{Cp})$ & $\bullet$ & 0 & & 0 & \\
\hline WE6 Cooling Tower Water Use & 2 & & & & & & & & & & \\
\hline WE7 Water Metering & 1 & & & & & & & & & & \\
\hline Energy and atmosphere (EA) & 33 & $30.00 \%$ & & & & & & 4 & $3.64 \%$ & 22 & $20.00 \%$ \\
\hline \multirow[t]{5}{*}{ EA1 Fundamental Commissioning and Verification } & & & \multirow[t]{5}{*}{ o } & \multirow[t]{5}{*}{$\bullet$} & F1.1 & $\mathrm{T} / \mathrm{CP}(\mathrm{Cr})$ & $\bullet$ & 0 & & 0 & \\
\hline & & & & & F1.2 & $T / C P(C p)$ & & & & & \\
\hline & & & & & F4.1 & $\mathrm{CP}(\mathrm{Cr} / \mathrm{Ct})$ & & & & & \\
\hline & & & & & F5.1 & $\mathrm{CP}(\mathrm{Cr} / \mathrm{Ct})$ & & & & & \\
\hline & & & & & F7.1 & $\mathrm{CP}(\mathrm{Cp})$ & & & & & \\
\hline EA2 Minimum Energy Performance & & & $\bullet$ & $\bullet$ & B1.1 & $\mathrm{T}(\mathrm{Cr} / \mathrm{Cp})$ & $\bullet$ & $\bullet$ & & 0 & \\
\hline & & & & & B11.. & $\mathrm{A}(\mathrm{Cr})$ & & & & & \\
\hline EA3 Building-Level Energy Metering & & & $\bullet$ & $\bullet$ & B3.1 & $\mathrm{T}(\mathrm{Cr} / \mathrm{Cp})$ & $\bullet$ & $\bullet$ & & 0 & \\
\hline & & & & & G1.1 & $\mathrm{T}(\mathrm{Cr})$ & & & & & \\
\hline EA4 Fundamental Refrigerant Management & & & 0 & & & & & & & & \\
\hline EA5 Enhanced Commissioning & 6 & & & $\bullet$ & F5.1 & $\mathrm{CP}(\mathrm{Cr} / \mathrm{Cp})$ & $\bullet$ & 0 & & 0 & \\
\hline & & & & & F7.1 & $\mathrm{CP}(\mathrm{Cp})$ & & & & & \\
\hline & & & & & G1.1 & $\mathrm{T}(\mathrm{Cr})$ & & & & & \\
\hline & & & & & G2.1 & $T(C p)$ & & & & & \\
\hline & & & & & G2.2 & $\mathrm{Ct}$ & & & & & \\
\hline EA6 Optimise Energy Performance & 18 & & & $\bullet$ & B1.3 & $T(C p)$ & $\bullet$ & 0 & & 18 & \\
\hline & & & & & B11.1 & $\mathrm{A}(\mathrm{Cr})$ & & & & & \\
\hline EA7 Advanced Energy Metering & 1 & & & $\bullet$ & F5.1 & $\mathrm{CP}(\mathrm{Cr} / \mathrm{Cp})$ & $\bullet$ & 1 & & 1 & \\
\hline & & & & & G2.1 & $T(C p)$ & & & & & \\
\hline EA8 Demand Response & 2 & & & & & & & & & & \\
\hline EA9 Renewable Energy Production & 3 & & & $\bullet$ & B4.1 & $\mathrm{T}(\mathrm{Cr})$ & $\bullet$ & 3 & & 3 & \\
\hline & & & & & B4.2 & $T(C p)$ & & & & & \\
\hline & & & & & B13 & $A(C p)$ & & & & & \\
\hline EA10 Enhanced Refrigerant Management & 1 & & & & & & & & & & \\
\hline EA11 Green Power and Carbon Offsets & 2 & & & & & & & & & & \\
\hline Materials and resources (MR) & 13 & $11.82 \%$ & & & & & & 0 & $0.00 \%$ & 4 & $3.64 \%$ \\
\hline MR1 Storing and Collecting Recyclables & & & $\bullet$ & $\bullet$ & B6.1 & $\mathrm{T}(\mathrm{Cr} / \mathrm{Cp})$ & $\bullet$ & $\bullet$ & & 0 & \\
\hline & & & & & F6.1 & $\mathrm{CP}(\mathrm{Cr} / \mathrm{Cp})$ & & & & & \\
\hline & & & & & G3.1 & $\mathrm{T}(\mathrm{Cr})$ & & & & & \\
\hline & & & & & G3.2 & $T(C p)$ & & & & & \\
\hline & & & & & G3.3 & $\mathrm{CP}(\mathrm{Cr} / \mathrm{Cp})$ & & & & & \\
\hline MR2 Construction and Demolition Waste Management & & & $\bullet$ & $\bullet$ & D3.1 & $\mathrm{T} / \mathrm{CP}(\mathrm{Cr})$ & $\bullet$ & $\bullet$ & & 0 & \\
\hline & & & & & D3.2 & $\mathrm{T} / \mathrm{CP}(\mathrm{Cp})$ & & & & & \\
\hline
\end{tabular}




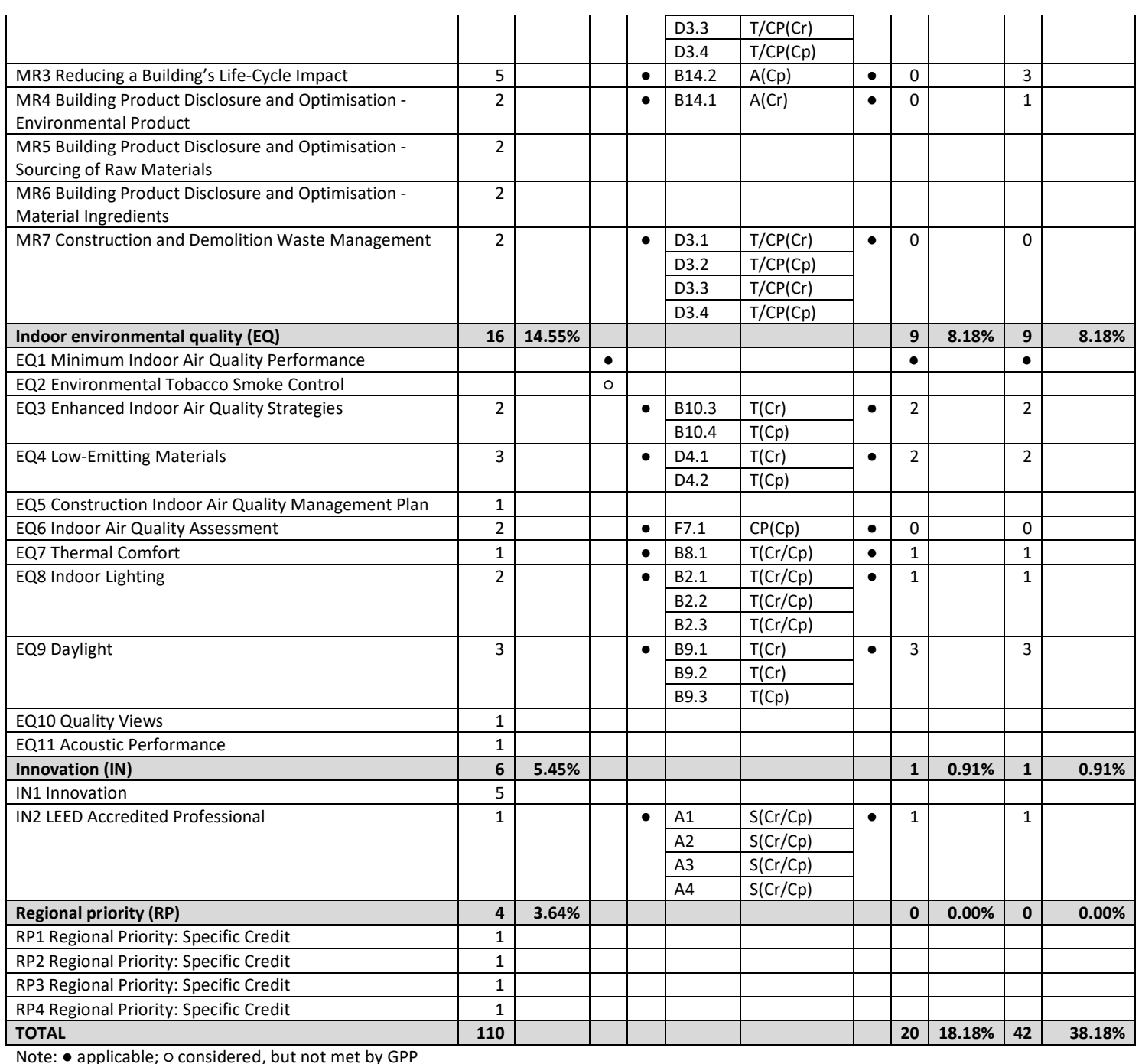

In LEED New Construction and Major Renovation, the increased score obtained is $18.18 \%$ with the standard scenario and $38.18 \%$ with the ambitious one, which is a notably bigger difference than with BREEAM and VERDE. Indoor environmental quality (EQ), Energy and atmosphere (EA) and Location and transportation (LT) are the most addressed areas. No differences appear between the standard and ambitious scenarios for EA and EQ, but the ambitious one for EA accounts for a bigger contribution because energy issues are a pre-requisite in this tool, and the further performance improvements achieved with GPP involve a significantly higher score. The development of a staff travel plan suggested by GPP is in accordance with the credits associated with transport (LT) and also indoor environmental quality (EQ) issues, such as air quality, thermal comfort and lighting, which fall in line with GPP criteria. Carrying out an LCA of a building and using EPD for construction products, linked to the GPP award criteria, help enhance the performance of the Materials and resources (MR) area. As with BREEAM and VERDE, site and location issues are not addressed by GPP. Here some of the pre-requisites introduced by LEED are not met with GPP, which acts as a barrier to achieving a class in the tool, namely: implementation of an erosion and sedimentation control plan for all construction activities associated with the project (SS1), water issues concerning reduced use and metering (WE1, WE2, WE3 and EA1), responsible use of refrigerants (EA4), and minimising exposure of occupants to tobacco smoke (EQ2). These considerations should be taken into account by project designers and managers when submitting a bid proposal to obtain the LEED label. 
Table 6. Calculating the rate of improvement achieved by applying GPP in VERDE Equipamiento

\begin{tabular}{|c|c|c|c|c|c|c|c|}
\hline Area/Indicator & 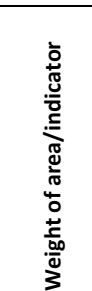 & 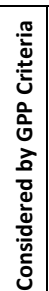 & 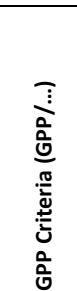 & $\begin{array}{l}\frac{0}{0} \\
\frac{0}{3} \\
\frac{1}{0} \\
\frac{1}{5} \\
\text { s }\end{array}$ & 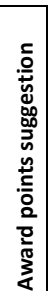 & 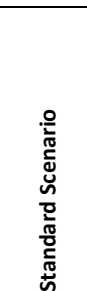 & 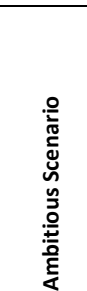 \\
\hline Site (PyE) & $16.25 \%$ & & & & & $6.22 \%$ & $6.22 \%$ \\
\hline PyE01 Proximity to public transport & $2.21 \%$ & $\bullet$ & B5.1 & $\mathrm{T}(\mathrm{Cr} / \mathrm{Cp})$ & $\bullet$ & $2.21 \%$ & $2.21 \%$ \\
\hline PyE02 Proximity to amenities & $2.21 \%$ & & & & & & \\
\hline PyE03 Cycling facilities & $2.21 \%$ & $\bullet$ & B5.2 & $\mathrm{T}(\mathrm{Cr} / \mathrm{Cp})$ & $\bullet$ & $2.21 \%$ & $2.21 \%$ \\
\hline PyE04 Electric vehicle recharging points capacity & $1.17 \%$ & $\bullet$ & B5.3 & $\mathrm{T}(\mathrm{Cr} / \mathrm{Cp})$ & $\bullet$ & $1.17 \%$ & $1.17 \%$ \\
\hline \multirow{2}{*}{ PyE05 Waste segregation } & \multirow[t]{2}{*}{$1.25 \%$} & \multirow[t]{2}{*}{$\bullet$} & B6.1 & $\mathrm{T}(\mathrm{Cr} / \mathrm{Cp})$ & \multirow[t]{2}{*}{$\bullet$} & \multirow[t]{2}{*}{$0.63 \%$} & \multirow{2}{*}{$0.63 \%$} \\
\hline & & & F6.1 & $\mathrm{CP}(\mathrm{Cr} / \mathrm{Cp})$ & & & \\
\hline PyE06 Managing and restoring the natural habitat & $2.21 \%$ & & & & & & \\
\hline PyE07 Use of vegetation for shading & $2.35 \%$ & & & & & & \\
\hline PyE08 Heat island & $1.66 \%$ & & & & & & \\
\hline PyE09 Light pollution & $1.25 \%$ & & & & & & \\
\hline Energy and atmosphere (EyA) & $20.66 \%$ & & & & & $0.00 \%$ & $3.15 \%$ \\
\hline \multirow[t]{2}{*}{ EyA01 Heating and cooling demands } & \multirow[t]{2}{*}{$8.52 \%$} & \multirow[t]{2}{*}{$\bullet$} & B1.3 & $T(C p)$ & \multirow{2}{*}{$\bullet$} & & \multirow[t]{2}{*}{ (2) } \\
\hline & & & F1 & $\mathrm{T} / \mathrm{CP}(\mathrm{Cr} / \mathrm{Cp})$ & & & \\
\hline EyA02 Non-renewable primary energy use & $5.05 \%$ & $\bullet$ & B1.1 & $\mathrm{T}(\mathrm{Cr} / \mathrm{Cp})$ & $\bullet$ & & \\
\hline \multirow[t]{2}{*}{ EyA03 $\mathrm{CO}_{2}$ emissions } & $3.15 \%$ & $\bullet$ & B1.1 & $\mathrm{T}(\mathrm{Cr} / \mathrm{Cp})$ & & & $3.15 \%$ \\
\hline & & & B11.1 & $\mathrm{A}(\mathrm{Cr})$ & $\bullet$ & & \\
\hline EyA04 Use in transportation systems & $1.42 \%$ & & & & & & \\
\hline EyA05 Responsible use of refrigerants & $2.52 \%$ & & & & & & \\
\hline Natural resources (RN) & $24.60 \%$ & & & & & $5.61 \%$ & $15.78 \%$ \\
\hline RN01 Water use in toilets & $3.15 \%$ & $\bullet$ & B7.1 & $\mathrm{T} / \mathrm{A}(\mathrm{Cr} / \mathrm{Cp})$ & $\bullet$ & $3.15 \%$ & $3.15 \%$ \\
\hline RN02 Gardening irrigation & $1.89 \%$ & & & & & & \\
\hline RN03 Water use in singular elements & $0.00 \%$ & & & & & & \\
\hline RN04 Non-drinking water use & $1.89 \%$ & & & & & & \\
\hline RN05 Recycled material use & $1.58 \%$ & $\bullet$ & B15.1 & $\mathrm{A}(\mathrm{Cr})$ & $\bullet$ & & $1.58 \%$ \\
\hline & & & B15.2 & $A(C p)$ & & & \\
\hline & & & D5.1 & $\mathrm{CP}(\mathrm{Cr} 7 \mathrm{Cp})$ & & & \\
\hline RN 06 Use of materials from sustainable sources & $1.26 \%$ & $\bullet$ & D1.1 & $\mathrm{T} / \mathrm{Cp}(\mathrm{Cr} / \mathrm{Cp})$ & $\bullet$ & $0.88 \%$ & \\
\hline RN 07 Use of local materials & $2.52 \%$ & & & & & & \\
\hline RN 08 Selective demolition strategy & $1.58 \%$ & $\bullet$ & C1.1 & $\mathrm{T}(\mathrm{Cr})$ & $\bullet$ & $1.58 \%$ & $1.58 \%$ \\
\hline & & & C1.2 & $T(C p)$ & & & \\
\hline & & & C1.3 & $\mathrm{T}(\mathrm{Cr} / \mathrm{Cp})$ & & & \\
\hline RN09 Construction and demolition waste management & $1.26 \%$ & $\bullet$ & D3.1 & $\mathrm{T} 7 \mathrm{CP}(\mathrm{Cr})$ & $\bullet$ & & \\
\hline & & & D3.2 & $\mathrm{T} / \mathrm{CP}(\mathrm{Cp})$ & & & \\
\hline & & & D3.3 & $\mathrm{T} / \mathrm{Cp}(\mathrm{Cr})$ & & & \\
\hline & & & D3.4 & $\mathrm{T} / \mathrm{CP}(\mathrm{Cp})$ & & & \\
\hline RN10 Impact of building materials & $6.95 \%$ & $\bullet$ & B12.1 & $\mathrm{A}(\mathrm{Cr} / \mathrm{Cp})$ & & & $6.95 \%$ \\
\hline & & & B14.2 & $A(C p)$ & & & \\
\hline RN11 Product eco-labelling & $2.52 \%$ & $\bullet$ & B12.1 & $\mathrm{A}(\mathrm{Cr} / \mathrm{Cp})$ & & & $2.52 \%$ \\
\hline & & & B14.1 & $\mathrm{A}(\mathrm{Cr})$ & & & \\
\hline Indoor air quality (CAI) & $18.92 \%$ & & & & & $10.30 \%$ & $10.30 \%$ \\
\hline CAI01 VOCs emissions & $3.15 \%$ & $\bullet$ & D4.1 & $\mathrm{T}(\mathrm{Cr})$ & $\bullet$ & $2.10 \%$ & $2.10 \%$ \\
\hline & & & D4.2 & $T(C p)$ & & & \\
\hline & & & F7.1 & $\mathrm{CP}(\mathrm{Cp})$ & & & \\
\hline CAI02 Air quality monitoring & $3.15 \%$ & & & & & & \\
\hline CAI03 Daylighting & $5.05 \%$ & $\bullet$ & B9.1 & $\mathrm{T}(\mathrm{Cr})$ & & $5.05 \%$ & $5.05 \%$ \\
\hline & & & B9.2 & $\mathrm{T}(\mathrm{Cr})$ & & & \\
\hline & & & B9.3 & $T(C p)$ & & & \\
\hline CAI04 Artificial lighting in working spaces & $3.15 \%$ & $\bullet$ & B2.1 & $\mathrm{T}(\mathrm{Cr} / \mathrm{Cp})$ & & $3.15 \%$ & $3.15 \%$ \\
\hline & & & $\mathrm{B} 2.3$ & $\mathrm{~T}(\mathrm{Cr} / \mathrm{Cp})$ & & & \\
\hline CAI05 Noise prevention & $4.42 \%$ & & & & & & \\
\hline Socio- economic aspects (ASE) & $4.73 \%$ & & & & & $0.00 \%$ & $0.00 \%$ \\
\hline ASE01 Universal accessibility & $2.84 \%$ & & & & & & \\
\hline ASE02 Visual access in working spaces & $1.89 \%$ & & & & & & \\
\hline Quality (CC) & $14.57 \%$ & & & & & $7.50 \%$ & $7.50 \%$ \\
\hline CC01 Efficiency in spaces design & $1.89 \%$ & & & & & & \\
\hline CCO2 Building Energy Management System & $3.48 \%$ & $\bullet$ & B3.1 & $\mathrm{T}(\mathrm{Cr} / \mathrm{Cp})$ & & $2.08 \%$ & $2.08 \%$ \\
\hline & & & B3.2 & $T(C r / C p)$ & & & \\
\hline & & & B3.3 & $T(C p)$ & & & \\
\hline & & & B3.4 & $\mathrm{T}(\mathrm{Cr} / \mathrm{Cp})$ & & & \\
\hline & & & B3.5 & $T(C p)$ & & & \\
\hline & & & F5.1 & $\mathrm{CP}(\mathrm{Cr} / \mathrm{Cp})$ & & & \\
\hline & & & G1.1 & $\mathrm{T}(\mathrm{Cr})$ & & & \\
\hline CC03 Partial operation of installation and technical systems & $1.26 \%$ & $\bullet$ & B3.3 & $T(C p)$ & & $1.26 \%$ & $1.26 \%$ \\
\hline CC04 Lighting control per zone in working spaces & $2.27 \%$ & $\bullet$ & B2.1 & $\mathrm{T}(\mathrm{Cr} / \mathrm{Cp})$ & & $2.27 \%$ & $2.27 \%$ \\
\hline
\end{tabular}




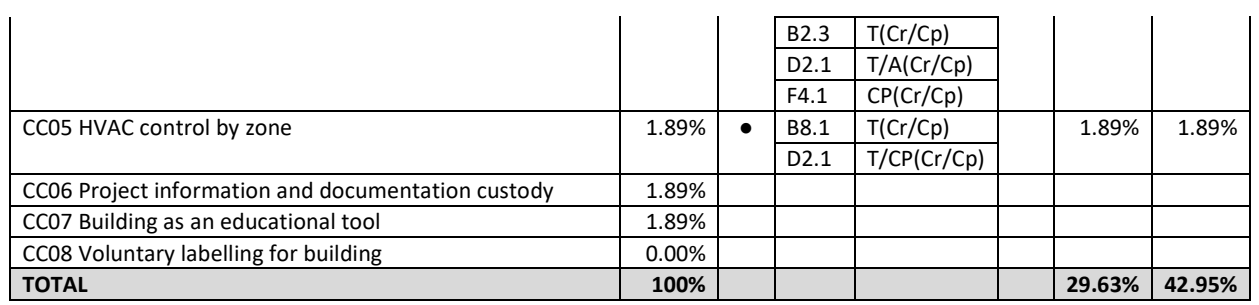

Note: $\bullet$ applicable

In VERDE Equipamiento, the standard and ambitious scenarios account for $29.63 \%$ and $42.95 \%$, respectively. It should be noted in this tool that the strongest impact results from implementing GPP. The most addressed areas are Natural resources (RN), Indoor air quality (CAI), Quality (CC) and Site (PyE), of which the last one is due to transport issues. No significant differences resulted from applying the standard and ambitious scenarios, except for RN and EyA, where a higher score is obtained with the ambitious scenario because of the greater reduction in $\mathrm{CO}_{2}$ emissions (EyA03), increased use of recycled materials (RNO5), the development of an LCA for construction products (RN10) and the use of eco-labels (RN11). The Energy and atmosphere (EyA) area is barely addressed by GPP for similar reasons to those in BREEAM. This means that the respective specifications between them do not match easily. Socio-economic aspects (ASE), which are specifically included in VERDE, but not in BREEAM and LEED, are not addressed by GPP. 


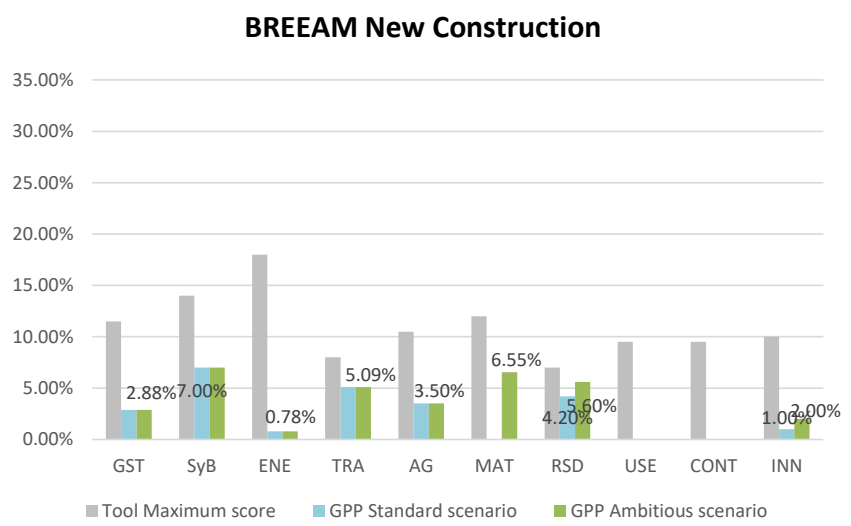

LEED New Construction and Major Renovations

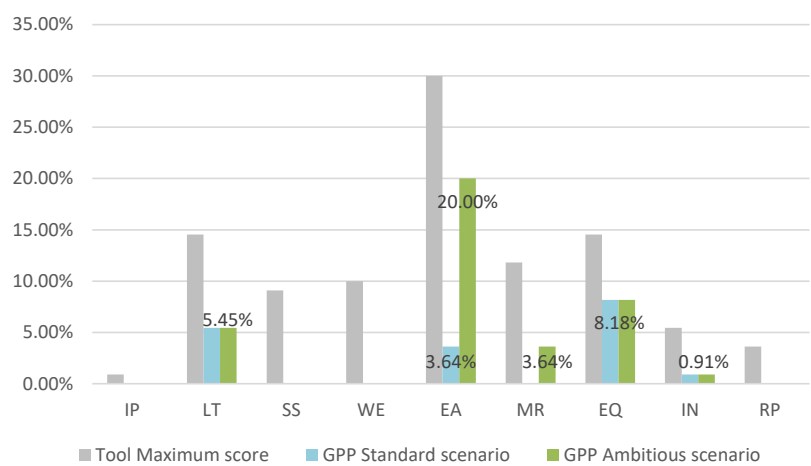

VERDE Equipamiento

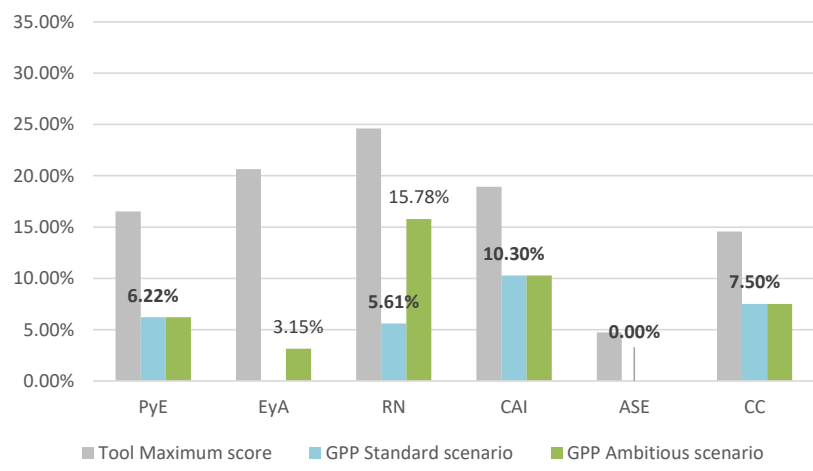

Figure 4. The score ratings obtained in the BSA tools by applying the standard and ambitious GPP scenarios

After this detailed analysis, Figure 4 graphically summarises the score rating results obtained in the three BSA tools from Tables 4,5 and 6 , as a result of applying GPP criteria through sustainability indicators. The first bar (grey) represents the maximum score that can be obtained in each topic. The second bar (blue) indicates the score as a percentage obtained in the topic when applying the GPP standard scenario, while the third bar (green) represents the score obtained after applying the ambitious scenario.

\subsection{Stage IV: BSA tools rating analysis and GPP weighting proposal}

\section{BSA tools rating analysis}

Once the level of fulfilment of the criteria between GPP and BSA has been analysed, it is possible to quantify the maximum score that can be achieved in the BSA tools by applying GPP criteria. Table 7 summarises those scores (\% or points, depending on the tool) for both 
scenarios defined in stage III of the methodology (standard and ambitious) in a hypothetical office building. It is considered that the office building can hold a certain initial project rating in the tool or not (varying from a non-certified project to a good performance level). According to the score improvement that can be achieved by applying GPP criteria, the maximum rating for the project is determined for each tool, depending on the initial rating.

Table 7. The BSA tools rating resulting from implementing GPP Criteria

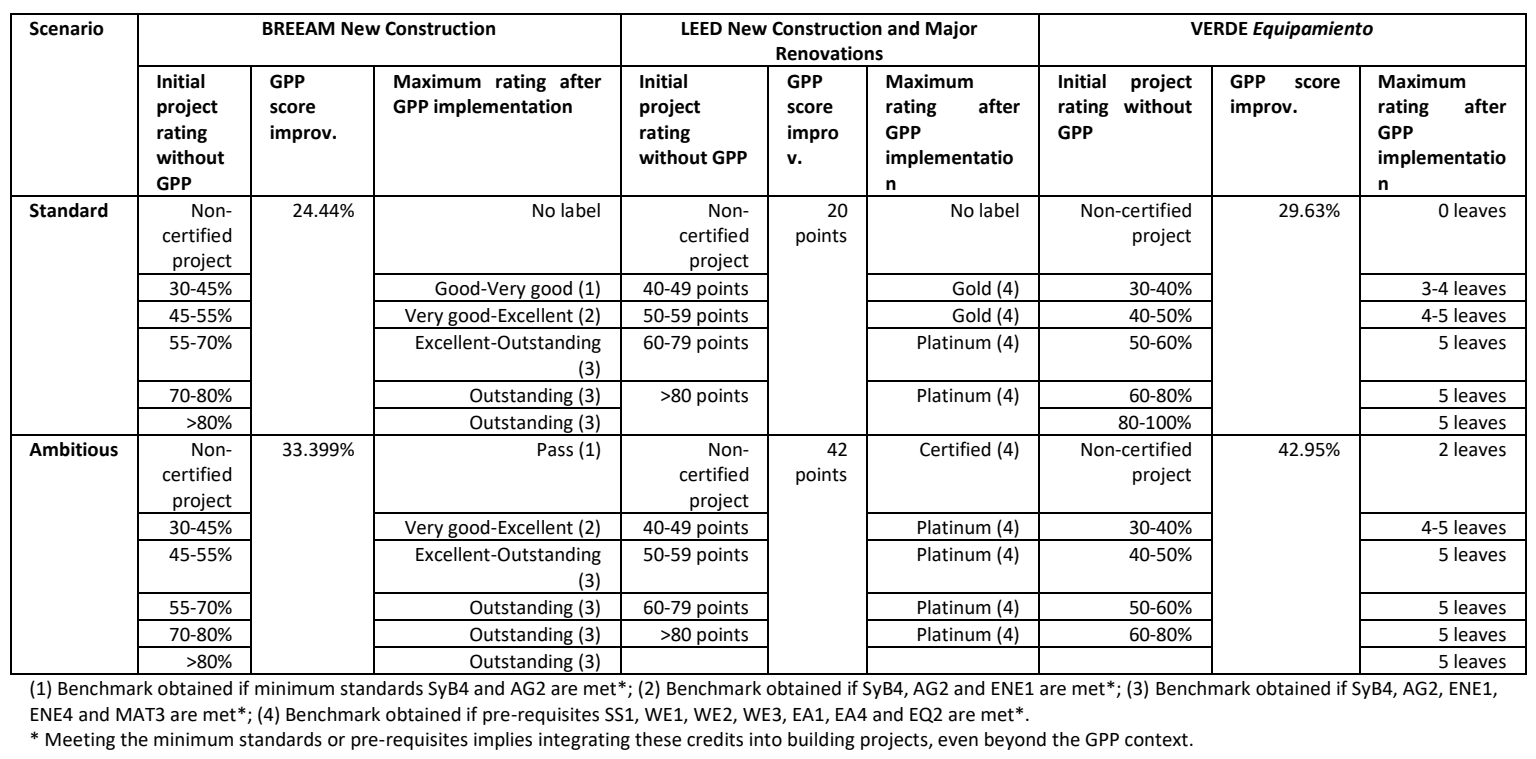

From this analysis, it is also possible to define the rating that is likely to be achieved depending on the initial rating of the building under study. By applying the GPP criteria to a building that was not previously certified by a BSA tool, it is possible to achieve the minimum score needed to obtain certification with any of the BSA tools analysed. As depicted in Table 7, the scores obtained by applying the GPP standard scenario in the three tools are $29.63 \%, 24.44 \%$ and 20 points in VERDE, BREEAM and LEED, respectively. However, the minimum score required to obtain the label is more than $30 \%$ in VERDE and BREEAM, and at least 42 points in LEED. Generally when the GPP standard scenario is implemented, acceptable ratings can be achieved if the building project has at least a minimum baseline benchmark. These are denoted by 3 or 4 leaves in VERDE, Good or Very good in BREEAM, and Gold in LEED. In non-certified building projects, applying the GPP ambitious scenario directly implies achieving a label in VERDE and BREEAM with "2 leaves" and the "Pass" classification, respectively, if the minimum requirements are met in the latter. Otherwise, if the building baseline project has a minimum label class, considering the targets set by the ambitious scenario makes it easier to achieve the highest building performance levels in all three BSA tools.

\section{GPP weighting proposal}

For those GPP criteria that are linked to one or more BSA criteria, as shown in Tables 4, 5 and 6 , a weighting range (\%) is proposed based on the existing weights of the BSA tools. This proposal is presented in Figure 5. Only four GPP criteria are not covered by BSA (GPP/B16, GPP/E1, GPP/F2 and GPP/G3), and so a minimum percentage of $0-1 \%$ has been assigned. This proposal establishes a weighting system that can be used as a reference by public authorities for awarding points to tenders during the evaluation process. Since it is based on the 
weightings proposed by the BSA tools, the process gains objectivity and assists authorities in making informed decisions.

As can be seen in Figure 5, addressing the energy performance of the building (GPP/B1) acquires the most importance with an advisable range of $20-28 \%$ of the awarding points in the evaluation of tenders. This is followed by the establishment of a staff travel plan and infrastructure (GPP/B5), with 9-12\%; taking into account the performance of the main building elements through EPD or LCA (GPP/B14), with 7-11\%; managing water saving installations (GPP/B7), with 5-11\%; considering daylighting and glare control (GPP/B9), with 4-8\%; and minimising the building life cycle global warming potential (GPP/B12), with 4-8\%.

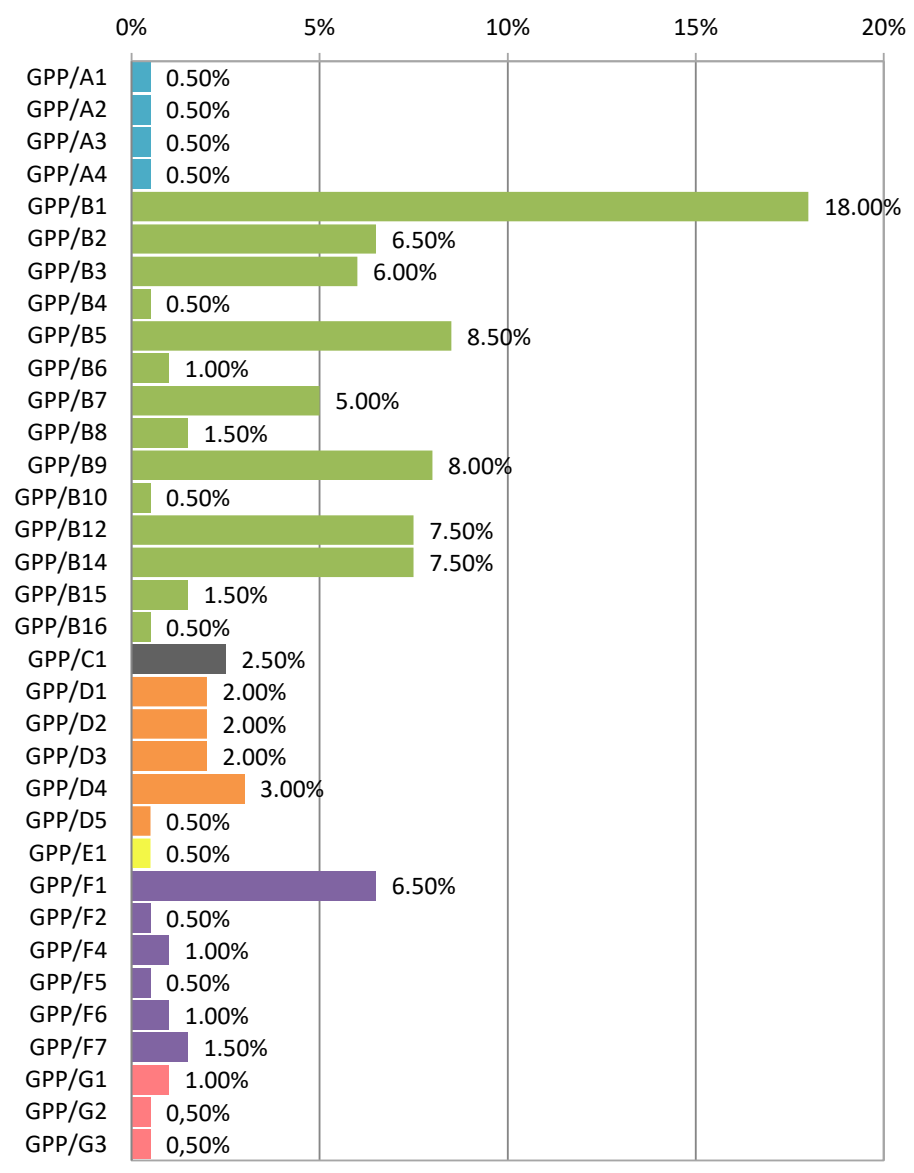

Figure 5. Weighting proposal for rating GPP criteria in tender evaluation processes (\% range)

\section{Discussion}

Several findings can be drawn from applying the GPP standard and ambitious scenarios to BSA tools. The specific conclusions that discuss all 14 topics clustered according to Figure 3 are described as follows.

The topic Site includes issues about the impact that the building's location has on the environment. Thus, BSA tools encourage the use of previously occupied or contaminated land, avoiding land that has not been previously disturbed. Although the tools pay attention to this topic, GPP does not address it and focuses only on the building itself, and not on the location and surroundings. However, as specific local conditions affect the building's environmental performance in its use stage, the definition of tendering criteria should be adapted to them (Testa et al. 2016). 
The standard GPP scenario largely covers aspects related to Transport and mobility in the three tools with the development of a staff travel plan to reduce their need to commute to the building privately by car, and to promote the use of more sustainable transport alternatives, such as walking and cycling, low-emission vehicles, public transport and car-sharing options. The provision of secure, easily accessible bicycle storage and recharging points for electric vehicles is considered in GPP, according to the related indicators included in the tools. Generally, the conditions for measuring the criteria included in the tools are specified in detail, while GPP provides more general guidance. For instance, VERDE details the number of public transport stops within a specific radius of action depending on the number of inhabitants in a city, and establishes the required number of recharging points for electric vehicles. With BREEAM, an accessibility index should be calculated according to the distance to node and the average frequency per hour. Apart from these initiatives, LEED also encourages the use of green vehicles by providing preferred parking spaces and shower rooms with changing facilities to promote the use of cycling and physical activity by workers.

Nature and biodiversity have barely any repercussion, as GPP does not consider issues such as preserving the habitat's ecological value, enhancing site ecology and minimising long-term impacts on biodiversity. Although the working document to develop GPP criteria recognises the contribution made to reduce impacts, there are no criteria to consider this. The specific measures envisaged by BSA could also be integrated into GPP, such as green walls and roofs, or habitats in courtyards, or Sustainable Urban Drainage Systems (SUDS), which can offer many advantages while supporting biodiversity. For instance, notable benefits include improving thermal efficiency through natural cooling, enhancing indoor air quality and making the working environment more attractive and productive, and limiting rain-water run-off.

The topic Energy is one of the main focal points in GPP for office buildings, and aims to accomplish the EPBD energy efficiency requirements (EPBD 2010), especially so that buildings owned by Public Administrations can become Net-Zero Energy Buildings (NEZB). However, there is a minor correspondence between the guidelines provided by GPP and those from BSA tools, due mainly to the relatively low score achieved in the energy field. In terms of buildings' energy efficiency, GPP establishes minimum energy performance based on three limits: holding a class B Energy Performance Certificate, double the $\mathrm{kWh} / \mathrm{m}^{2}$ cut-off value for the best class or a maximum of $100 \mathrm{kWh} / \mathrm{m}^{2}$ (the strictest) for new buildings (similar, but less restrictive limits for renovations), and these being in accordance with EPBD (2010). Sometimes tools adopt different criteria that are not always comparable. VERDE is based on the assumptions made by the Spanish Regulation (CTE 2013), which proposes limited energy demand and primary energy use according to the climate zone and the building's use, and also refers to related $\mathrm{CO}_{2}$ emissions. A score is given according to the proportional reductions compared to the legal requirements. The fulfilment of GPP criteria (B1.1-B1.3) here in the standard scenario does not guarantee compliance with VERDE. The GPP ambitious scenario, however, allows for increased ratings due to reduced $\mathrm{CO}_{2}$ emissions (EyA 03). BREEAM also approaches this issue by taking into account the energy demand, primary energy use and $\mathrm{CO}_{2}$ emissions of the building and by calculating an energy performance ratio. Likewise, GPP does not guarantee the score in BREEAM (ENE1) for both the standard and ambitious scenarios. In LEED, minimum building energy efficiency is required as a pre-requisite credit (EA2), which is accomplished by GPP. Then an optimised energy performance level grants points (EA6), which is fulfilled by the ambitious scenario of GPP. As we can see, passive building design strategies (e.g. energy demand limitation, use of vegetation for shading or use of natural ventilation) are not covered by GPP, but should be in the spotlight as urged by EPBD (2010), and are also recognised by international building standards like Passivhaus (Passivhaus Institut 1990). GPP should more consistently incorporate and support passive design strategies for buildings. 
Concerning energy, low-carbon technologies and energy-efficient building systems are promoted by GPP. BREEAM requires a viability study to determine the possibilities of using renewable energy and an LCA of the systems selected to estimate emissions (embedded and associated with the building's operation) by considering a 60-year lifespan. GPP does not cover this aspect, but encourages meeting a minimum of $10 \%$ of the primary energy demand through the use of renewable energy sources or high-efficiency and cost-effective alternative systems fitted in the curtilage of buildings.

The topic Energy is finally completed by incorporating a Building Energy Management System (BEMS). GPP promotes the installation of a BEMS to provide both users and managers with real-time information on the building's energy use. A user interface should allow comfort conditions to be adjusted in different zones by analysing and downloading information without the need for any specific training on the part of users. GPP suggests that BEMS should be considered in the building project and then, during completion and handover, it is commissioned to monitor the building's energy performance. Both BREEAM and LEED consider installing BEMS (credits ENE2 and EA3, respectively): in this case, their requirements are less restrictive than GPP. VERDE, however, does not include BEMS.

Water use is approached by GPP with criteria B7.1, which refers to the specific EU GPP Criteria for sanitary tapware and toilets. Like GPP, the BSA tools suggest reducing drinking water for sanitary use by limiting the water flow rate $(1 / \mathrm{min})$. By applying the GPP standard scenario, credit RNO1 in VERDE and credit AG1 in BREEAM are met, but not WE2 and WE5 in LEED because, apart from accomplishing water flow limits, sanitary devices must be WaterSenselabelled. Unlike GPP, the BSA tools also incorporate water monitoring. This issue should also be taken into account by GPP tenders, and in the same way as energy usage is monitored while the building is in use. Furthermore, BSA tools consider outdoor water use for irrigation and reusing non-drinking water for toilets and urinals, which are not considered in GPP. Greater efforts need to be made to include water monitoring and verification criteria in GPP.

The topic Materials is clearly addressed by GPP, which, among other aspects, promotes the incorporation of $15-30 \%$ of recycled content into concrete and masonry (structural frame and foundation, walls, floor, ceilings and roofs) as an award criterion to give points to tenderers. By considering the award criteria from the GPP ambitious scenario, VERDE and BREEAM credits RN05 and RSD2 are met. During construction work, the lead contractor is called to source legally harvested timber, which falls in line with VERDE (RNO6). The use of construction products with EPD and conducting an LCA for the building's main elements are awarded points by the GPP for the bidders who include them, and so they are very important. The three tools include credits for this topic, which are generally covered by the GPP ambitious scenario. VERDE credits that encourage using low environmental-impact materials and eco-labels (RN10 and RN11), those from BREEAM for conducting an LCA (MAT1) and LEED for building life-cycle impact reduction and the use of EPDs (MR3 and MR4) are met by the GPP award criteria, which raise scores to a notable extent in the BSA tools. Other aspects, such as using local products (RNO7 in VERDE), employing responsible insulation materials in the building's envelope and accurate design for the protection and durability of materials (MAT4 and MAT5 in BREEAM) are considered in BSA tools, but not in GPP. However, these are relevant aspects that may be incorporated into tender documents when a building is being bid for.

Waste management is also a hot topic in GPP with two main focal points. One of them refers to providing a space for recyclable waste storage in the building to facilitate the segregation of end-of-life products and recyclable materials, while the other concerns construction and demolition waste management during construction work. Both are covered by BSA tools and GPP criteria to ensure good levels of compliance. LEED includes them as pre-requisites (MR1 and MR2), which are fully met by GPP. VERDE and LEED encourage the development of a selective demolition plan to provide exhaustive waste measurement and guidance on how to 
reuse waste in works. BREEAM also proposes providing the building with a static waste compactor and a vessel for composting, which are not covered by GPP.

Pollution is an issue that is not addressed by GPP. BSA tools integrate several credits related to this topic, specifically controlling water, soil, air (emissions such as NOx) and acoustic pollution or night lighting; selecting and using refrigerants in a responsible way; and minimising pollution during construction activities. In this respect, greater efforts should be made by GPP.

Living environment is well covered by GPP. In this topic, and according to the BSA tools, aspects like indoor air quality, lighting and visual quality, acoustic protection, thermal comfort and reduced emissions from materials and finishes are included. GPP suggests a ventilation system for buildings to provide an air quality of IDA 1 in accordance with EN 15251 (BSI RHE/2, 2007), taken far away from sources of pollution. GPP also recommends that most of the surface area of the working space should have optimum daylighting and glare levels to support dynamic modelling calculations. Thermal comfort levels should be in line with EN 15251 and must also be demonstrated by using dynamic simulation software on an hourly basis. The selection of fit-out materials and finishes to accomplish the emission limits of VOCs, formaldehyde and carcinogens (trichloroethylene, benzene, etc.) is also required by GPP, which correlates well with the limits established by the BSA tools. Meanwhile, GPP approaches do not monitor air quality while the building is in operation or acoustic issues, which should both be considered.

Design and efficiency refers to an appropriate building design to achieve optimum operation levels. Here GPP is quite in tune with VERDE by providing good scores in the tool. One example of this is the capacity of occupiers to partially operate technical systems (CCO3), enable HVAC (CC05) and control lighting systems (CCO4) by zones or working spaces. However, credit SyB6 in BREEAM, which encourages safe and secure use of access to and from the building, and a credit for an integrative process in LEED, which supports cost-effective project outcomes with an early analysis of the interrelationships among systems (particularly energy and waterrelated systems), are not covered by GPP.

Management is a topic that is especially addressed by GPP once construction works have finished, and the building is commissioned and operating in the use stage. In contrast, BSA tools do not pay much attention to management, as only BREEAM (GST1 and GST3) and VERDE ( $\mathrm{CCO} 2$ and $\mathrm{CC06}$ ) include a few related credits. These are connected to the provision of a oneyear aftercare to ensure that the building operates and adapts according to design and demands, the provision of a building management system to control operational parameters, and also the provision of custody for project information and documentation. GPP, however, goes beyond the scope of BSA tools, including clauses such as signing an energy performance contract (EPC) with an ESCo (Energy Services Company), providing a waste management system, performing a test of the quality of the completed building fabric and indoor air, and checking the functioning of the lighting control systems and low-carbon technologies implemented in the building, all of which are conducted after completion and handover. BSA should pay more attention to the aftercare of a building in its operation stage as the use stage accounts for most of the influence of the building's entire lifecycle.

Innovation is motivated by introducing additional measures into the building to improve its performance. LEED encourages the development of projects to achieve exceptional or innovative performance, and also to incorporate an accredited professional into the team to streamline the application and certification process. BREEAM supports innovation by recognising additional sustainable benefits that are not rewarded by standard BREEAM issues, and by awarding extra points. Innovation is not specifically referred to in GPP as such, but many criteria help incorporate innovative initiatives, like the selection of the design team and contractors according to their level of competence in environmental knowledge and training 
(criteria GPP/A1-A4), which is covered by selection criteria (S). Selection of the project team is covered by the selection criteria (S) in GPP. Although these are especially important for achieving successful project completion, they were mostly lacking in tenders (Testa et al. 2016), and perhaps should be a minimum requirement for bidders to participate in tender proposals.

Social aspects are barely addressed by BSA tools. Only BREEAM and VERDE include some social criteria, namely: stakeholder involvement during the building process (GST4), universal design (ASE01), visual access from working areas (ASE02) and the building's use as an educational tool (CC07). Neither are social issues approached by GPP but, as Directive 2014/24/EU on public procurement $(E C, 2014)$ sets out, social requirements should be included in tender documents to spur social innovation and to address major societal challenges to, in turn, promote sustainable economic growth.

Economic issues involve assessing costs during the project design, construction and service life of the building. They are addressed only by BREEAM, in which credit GST5 encourages the use of Life Cycle Costing (LCC) (ISO, 2017) to improve design, specifications, through-life maintenance and operation to promote economic sustainability. Yet, GPP does not specifically fulfil this credit as it takes a more general approach by integrating LCC considerations into several GPP criteria. Thus GPP criteria will positively influence some key factors that affect a building's overall life cycle costs. During acquisition, the selection criteria (S) ensure that skilled stakeholders will cut the risk of cost overruns and will promote innovation. The arrangement of an EPC, early appraisal of options and resources-efficient construction are supported by a number of GPP criteria. During operation and maintenance, GPP considers water and energy efficiency performance criteria to optimise costs, addresses the quality of construction and the fitting and commissioning of HVAC systems and renewable technologies, promotes energy monitoring through a BEMS and suggests carrying out an LCA of the building to optimise its lifespan as a whole. It also includes other criteria concerning demolition waste management, a design for the building's future adaptability, and intangible benefits for human well-being that influence user comfort, amenity, health and work productivity.

\section{Conclusions}

This study has critically reviewed the criteria proposed in GPP for office buildings and crosschecked them against the sustainability indicators included in three BSA tools to reinforce the GPP framework and process for the office buildings sector. The aim of the study is to serve as a guidance tool to help public authorities in the process of evaluating the proposals in tenders and to establish a system for awarding points, based on the indicators proposed by the BSA tools.

Considering all the points discussed above, the aspects that are mainly approached by GPP criteria are Energy, Waste, Materials, Living environment, Management and Transport, in that order of relevance, and they are also matched with the relevant topics in the BSA tools. So a strong relationship between the two policy instruments, GPP and BSA, was identified, both of them having a lot to learn from the other. Indeed, it is noted that although BSA tools generally include a wider scope of topics than GPP, the latter goes more deeply into several topics, such as Management after the building's completion and LCC issues in the Economic aspect. These, then, may also be incorporated into the BSA, which represents a field for discussion in future work.

From the findings of the study, two main aspects should be highlighted. As regards the rate of improvement, VERDE is the tool in which GPP criteria provide the most marked increase and involves the best building performance level. Nevertheless, in general, the implementation of the three tools analysed (VERDE, BREEAM and LEED) confers good performance levels on GPP. 
Conversely, as identified from the literature review, it should be noted that GPP does not offer a score system to evaluate bidders' proposals quantitatively, but instead indicators provided by BSA and their weight can help contracting authorities to score them objectively. This study therefore proposed a set of weighting ranges for awarding points to tenders during the bidding process, thereby introducing an objective viewpoint based on reliable and proven sustainability indicators.

Both GPP and BSA tools, as policy instruments contributing to the challenge of moving towards a more sustainable economy, were identified as closely related and their content analysis provided interesting, albeit so far unexplored, findings. The results of the study will help contracting authorities to introduce more objectivity into the tendering process and to make informed decisions while evaluating bidders' proposals. 


\section{References}

Al-Qawasmi J. Examining indicators coverage in a sample of sustainable building assessment systems assessment systems. Archit Eng Des Manag. Taylor \& Francis; 2018;1-20.

Bernardi E, Carlucci S, Cornaro C, Bohne RA. An Analysis of the Most Adopted Rating Systems for Assessing the Environmental Impact of Buildings. Sustainability. 2017;9(1226):1-27.

Braulio-Gonzalo M, Bovea MD, Ruá MJ. Sustainability on the urban scale: Proposal of a structure of indicators for the Spanish context. Environ Impact Assess Rev. Elsevier Inc.; 2015;53:16-30.

BRE Global. Building Research Establishment Environmental Assessment Method [Internet]. United Kingdom; 1990. Available from: https://www.breeam.com/

British Standards Institution (BSI RHE/2). EN 15251:2007 Indoor environmental input parameters for design and assessment of energy performance of buildings addressing indoor air quality, thermal environment, lighting and acoustics. 2007.

Cole RJ. Building environmental assessment methods: Redefining intentions and roles. Build Res Inf. 2005;33(5):455-67.

COM 400. Public procurement for a better environment. Communication from the Commission to the European Parliament, the Council, the European Economic and Social Committee and the Committee of the Regions. Brussels; 2008.

CTE. Orden FOM/1635/2013, de 10 de septiembre, por la que se actualiza el Documento Básico DB-HE Ahorro de Energía del Código Técnico de la Edificación, aprobado por Real Decreto 314/2006, de 17 de marzo. Orden FOM/1635/2013 España; 2013.

D'Hollander D, Marx A. Strengthening private certification systems through public regulation: The case of sustainable public procurement. Sustain Accounting, Manag Policy J. 2014;5(1):2-21.

Deambrogio E, Allegretti S, Turi P, Zuccarello F, Lariccia P, Aghemo C, et al. Increase Sustainability in Buildings Through Public Procurements: The PROLITE project for Lighting Retrofit in Schools. Energy Procedia. 2017;111:328-37.

Dodd N, Cordella M, Traverso M, Donatello S. Level(s) - A common EU framework of core sustainability indicators for office and residential buildings: Parts 1 and 2. EUR 28899 EN. Luxembourg: Publications Office of the European Union; 2017.

Dodd N, Garbarino E, Gama-Caldas M. Green Public Procurement Criteria for office buildings design, construction and management. Procurement practice guidance document [Internet]. $2016 . \quad$ Available from: http://publications.jrc.ec.europa.eu/repository/bitstream/JRC102383/jrc102383_gpp_off ice buildings_guidance_final.pdf

EN 15978. Sustainability of construction works - Assessment of environmental performance of buildings - Calculation method. 2011.

EN ISO 15686-5. Buildings and constructed assets - Service life planning - Part 5: Life-cycle costing. International Organization for Standardization (ISO); 2017.

EPBD. European Directive 2010/31/UE on the energy performance of buildings [Internet]. 2010. Available from: http://eur-lex.europa.eu/legalcontent/EN/ALL/?uri=CELEX:32010L0031 
European Commission. Regulation (EC) No. 1221/2009 of the European Parliament and of the Council of 25 November 2009 on the voluntary participation by organisations in a Community eco-management and audit scheme (EMAS), repealing Regulation (EC) No. 761/2001 and Commission De [Internet]. European Union: Official Journal of the European Union; 2009a. Available from: https://eur-lex.europa.eu/legalcontent/EN/TXT/PDF/?uri=CELEX:32009R1221\&from=EN

European Commission. Regulation (EC) No 66/2010 of the European Parliament and the Council of 25 November 2009 on the EU Ecolabel [Internet]. 2009b. Available from: https://eur-lex.europa.eu/legal-content/EN/TXT/PDF/?uri=CELEX:32010R0066\&from=EN

European Commission. Directive 2012/27/EU of the European Parliament and of the Council of 25 October 2012 on energy efficiency. European Union: Official Journal of the European Union; 2012.

European Commission. Directive 2014/24/EU of the European Parliament and of the Council of 26 February 2014 on public procurement. Official Journal of the European Union; 2014.

European Commission. Buying green! A handbook on green public procurement. 3rd editio. Luxembourg: Publications Office of the European Union; 2016a.

European Commission. EU GPP Criteria for Office Building Design, Construction and Management. Brussels; 2016b.

European Communities. A lead market initiative for Europe. Communication from the Commission to the Council, The European Parliament, The European Economic and Social Committee and The Committee of the regions. Brussels; 2007.

Fuentes-Bargues JL, Ferrer-Gisbert PS, González-Cruz MC. Analysis of Green public procurement of works by Spanish public universities. Int J Environ Res Public Health. 2018;15(9).

Fuentes-Bargues JL, González-Cruz MC, González-Gaya C. Environmental criteria in the spanish public works procurement process. Int J Environ Res Public Health. 2017;14(2).

Giacomo MR De, Testa F, Iraldo F, Formentini M. Does Green Public Procurement lead to Life Cycle Costing (LCC) adoption? J Purch Supply Manag. Elsevier Ltd; 2018;1-10.

Green Building Council España (GBCe). VERDE Certificación [Internet]. 2002. Available from: https://gbce.es/certificacion-verde/

Haapio A, Viitaniemi P. A critical review of building environmental assessment tools. Environ Impact Assess Rev. 2008 Oct;28(7):469-82.

Huedo P, López-Mesa B. Revisión de herramientas de asistencia en la selección de soluciones constructivas sostenibles de edificación. Inf la Construcción. 2013 Jan 28;65(529):77-88.

iiSBE. International Initiative for Sustainable Building Environment [Internet]. 2004a. Available from: http://www.iisbe.org/

iiSBE. SBTool [Internet]. International Initiative for Sustainable Building Environment; 2004b. Available from: http://www.iisbe.org/sbmethod

ISO 14001. Environmental management systems - Requirements with guidance for use. International Organization for Standardization (ISO); 2015.

ISO 14040. Environmental management - Life Cycle Assessment - Principles and Framework. International Organization for Standardization (ISO); 2006. 
ISO 14044. Environmental management - Life cycle assessment - Requirements and guidelines. International Organization for Standardization (ISO); 2006.

Kajikawa $Y$, Inoue T, Goh TN. Analysis of building environment assessment frameworks and their implications for sustainability indicators. Sustain Sci. 2011;6(2):233-46.

Mahmoud S, Zayed T, Fahmy M. Development of sustainability assessment tool for existing buildings. Sustain Cities Soc. Elsevier; 2019;44:99-119.

Montalbán-Domingo L, García-Segura T, Sanz MA, Pellicer E. Social sustainability criteria in public-work procurement: An international perspective. J Clean Prod. 2018;198:1355-71.

Nordic Council of Ministers. Innovative Green Public Procurement of Construction, IT and Transport Services in Nordic countries. Copenhagen; 2010.

Passivhaus Institut. Passivhaus [Internet]. 1990 [cited 2019 Jan 16]. Available from: https://passivehouse.com/

SBA. Sustainable Building Alliance [Internet]. 2009. Available from: https://www.go-gba.org/

Sparrevik M, Wangen HF, Fet AM, De Boer L. Green public procurement - A case study of an innovative building project in Norway. J Clean Prod. Elsevier Ltd; 2018;188:879-87.

Sterner E. 'Green procurement' of buildings: A study of Swedish clients' considerations. Constr Manag Econ. 2002;20(1):21-30.

Tarantini M, Loprieno AD, Porta PL. A life cycle approach to Green Public Procurement of building materials and elements: A case study on windows. Energy. Elsevier Ltd; 2011;36(5):2473-82.

Testa F, Grappio P, Gusmerotti NM, Iraldo F, Frey M. Examining green public procurement using content analysis: existing difficulties for procurers and useful recommendations. Environ Dev Sustain. Springer Netherlands; 2016;18(1):197-219.

US GBC. LEED ND Leadership in Energy and Environmental Design for neighborhood development. The U.S. Green Building Council; 2009.

Uttam K, Balfors B. Green public procurement (GPP) of construction and building materials. In: Pacheco-Torgal F, Cabeza LF, Labrincha J, Magalhães A de, editors. Eco-efficient Constr Build Mater. Woodhead Publishing Limited; 2014. p. 166-95.

Uttam K, Le Lann Roos C. Competitive dialogue procedure for sustainable public procurement. J Clean Prod. Elsevier Ltd; 2015;86:403-16.

Varnäs A, Balfors B, Faith-Ell C. Environmental consideration in procurement of construction contracts: current practice, problems and opportunities in green procurement in the Swedish construction industry. J Clean Prod. 2009;17(13):1214-22.

WGBC. World Green Building Council [Internet]. 1990. Available from: https://www.worldgbc.org/ 